\title{
Drought Tolerant Enterobacter sp./Leclercia adecarboxylata Secretes Indole-3-acetic Acid and Other Biomolecules and Enhances the Biological Attributes of Vigna radiata (L.) R. Wilczek in Water Deficit Conditions
}

\author{
Bilal Ahmed 1,*(D), Mohammad Shahid ${ }^{2}\left(\mathbb{D}\right.$, Asad Syed ${ }^{3}$, Vishnu D. Rajput ${ }^{4} \mathbb{D}$, Abdallah M. Elgorban ${ }^{3}(\mathbb{D}$, \\ Tatiana Minkina ${ }^{4}$, Ali H. Bahkali ${ }^{3}$ and Jintae Lee ${ }^{1, *}$
}

Citation: Ahmed, B.; Shahid, M. Syed, A.; Rajput, V.D.; Elgorban, A.M.; Minkina, T.; Bahkali, A.H.; Lee, J. Drought Tolerant Enterobacter sp./Leclercia adecarboxylata Secretes Indole-3-acetic Acid and Other Biomolecules and Enhances the Biological Attributes of Vigna radiata (L.) R. Wilczek in Water Deficit Conditions. Biology 2021, 10, 1149. https://doi.org/10.3390/ biology10111149

Academic Editors: Ana Alexandre and Kathrin Wippel

Received: 31 August 2021

Accepted: 1 November 2021

Published: 8 November 2021

Publisher's Note: MDPI stays neutral with regard to jurisdictional claims in published maps and institutional affiliations.

Copyright: (c) 2021 by the authors. Licensee MDPI, Basel, Switzerland. This article is an open access article distributed under the terms and conditions of the Creative Commons Attribution (CC BY) license (https:/ / creativecommons.org/licenses/by/ $4.0 /)$.
1 School of Chemical Engineering, Yeungnam University, Gyeongsan 38541, Korea

2 Department of Agricultural Microbiology, Faculty of Agricultural Sciences, Aligarh Muslim University, Aligarh 202002, India; gd4858@myamu.ac.in

3 Department of Botany and Microbiology, College of Science, King Saud University, P.O. Box 2455, Riyadh 11451, Saudi Arabia; assyed@ksu.edu.sa (A.S.); aelgorban@ksu.edu.sa (A.M.E.); abahkali@ksu.edu.sa (A.H.B.)

4 Academy of Biology and Biotechnology, Southern Federal University, 344090 Rostov-on-Don, Russia; rvishnu@sfedu.ru (V.D.R.); tminkina@mail.ru (T.M.)

* Correspondence: bilal22000858@yu.ac.kr (B.A.); jtlee@ynu.ac.kr (J.L.)

Simple Summary: Drought stress is one of the most important factors that significantly affects agricultural lands and reduces the production of various crops. Among bean crops, Vigna radiata (mung bean) is a highly nutritious food crop that provides protein, carbohydrates, several essential minerals, amino acids, vitamins, and antioxidants. To resolve the problem of drought-affected agriculture of mung bean, we focused on finding a novel and sustainable solution by using a drought-tolerant bacterium Enterobacter sp./Leclercia adecarboxylata PAB19 that produces significant amounts of plant growth-promoting bioactive compounds and colonizes the roots of mung bean plants. By performing a series of in vitro and in situ (on field) experiments, we conclude that the bacterium PAB19 holds a great potential to mitigate drought stress. Several agriculturally important parameters were enhanced by the bacterial activity which was suppressed by the drought stress induced by a chemical PEG-6000 without bacterial inoculation. Conclusively, strain PAB19 can be applied to alleviate drought stress by improving the biological attributes of mung bean under water-deficit conditions.

Abstract: Drought or water stress is a limiting factor that hampers the growth and yield of edible crops Drought-tolerant plant growth-promoting rhizobacteria (PGPR) can mitigate water stress in crops by synthesizing multiple bioactive molecules. Here, strain PAB19 recovered from rhizospheric soil was biochemically and molecularly characterized, and identified as Enterobacter sp./Leclercia adecarboxylata (MT672579.1). Strain PAB19 tolerated an exceptionally high level of drought (18\% PEG-6000) and produced indole-3-acetic acid $\left(176.2 \pm 5.6 \mu \mathrm{g} \mathrm{mL}^{-1}\right)$, ACC deaminase $\left(56.6 \pm 5.0 \mu \mathrm{g} \mathrm{mL}^{-1}\right)$, salicylic acid (42.5 $\left.\pm 3.0 \mu \mathrm{g} \mathrm{mL}^{-1}\right)$, 2,3-dihydroxy benzoic acid (DHBA) $\left(44.3 \pm 2.3 \mu \mathrm{g} \mathrm{mL}^{-1}\right)$, exopolysaccharide $\left(204 \pm 14.7 \mu \mathrm{g} \mathrm{mL}^{-1}\right)$, alginate $\left(82.3 \pm 6.5 \mu \mathrm{g} \mathrm{mL}^{-1}\right)$, and solubilized tricalcium phosphate $\left(98.3 \pm 3.5 \mu \mathrm{g} \mathrm{mL}^{-1}\right)$, in the presence of $15 \%$ polyethylene glycol. Furthermore, strain PAB19 alleviated water stress and significantly $(p \leq 0.05)$ improved the overall growth and biochemical attributes of Vigna radiata (L.) R. Wilczek. For instance, at 2\% PEG stress, PAB19 inoculation maximally increased germination, root dry biomass, leaf carotenoid content, nodule biomass, leghaemoglobin ( $\mathrm{LHb}$ ) content, leaf water potential ( $\Psi \mathrm{L})$, membrane stability index (MSI), and pod yield by 10\%, 7\%, 14\%, 38\%, 9\%, $17 \%, 11 \%$, and $11 \%$, respectively, over un-inoculated plants. Additionally, PAB19 inoculation reduced two stressor metabolites, proline and malondialdehyde, and antioxidant enzymes (POD, SOD, CAT, and GR) levels in $V$. radiata foliage in water stress conditions. Following inoculation of strain PAB19 with $15 \%$ PEG in soil, stomatal conductance, intercellular $\mathrm{CO}_{2}$ concentration, transpiration rate, water vapor deficit, intrinsic water use efficiency, and photosynthetic rate were significantly improved by $12 \%, 8 \%$, 
$42 \%, 10 \%, 9 \%$ and $16 \%$, respectively. Rhizospheric CFU counts of PAB19 were 2.33 and $2.11 \log \mathrm{CFU} \mathrm{g}^{-1}$ after treatment with 15\% PEG solution and 8.46 and $6.67 \mathrm{log} \mathrm{CFU} \mathrm{g}^{-1}$ for untreated controls at 40 and 80 DAS, respectively. Conclusively, this study suggests the potential of Enterobacter sp./L. adecarboxylata PAB19 to alleviate water stress by improving the biological and biochemical features and of $V$. radiata under water-deficit conditions.

Keywords: drought stress; Enterobacter sp./L. adecarboxylata; growth regulating substances; Vigna radiata (L.) R. Wilczek; growth improvement; gas exchange parameters

\section{Introduction}

Crops face a wide range of environmental stresses [1,2], and drought stress now poses a major obstacle to global crop production sustainability [3]. Climate simulations predict drought stress will continue and become more severe [4,5], and it has been predicted that irrigation water demands will hugely increase by 2050 [6]. Drought stress affects plants morphologically, physiologically, and biochemically due to the generation of reactive oxygen species (ROS) $[7,8]$. Many approaches have been implemented recently to increase the drought tolerance of crops, such as conventional breeding and genetic engineering. However, these methods have certain limitations that prevent their utilization in agricultural practices [9]. In this regard, drought-tolerant rhizobacteria that promote plant development are considered a viable option for sustainable agriculture in water-scarce areas. Vigna radiata (mung bean), a widely grown nutrient-dense grain legume in the tropics, is noted for its detoxifying properties and is used to relieve heat exhaustion and minimize swelling in summer [10].

Beneficial rhizobacteria, often referred to as plant growth-promoting rhizobacteria (PGPR), have an important role in plant development, nutrition management, and biocontrol activities [11-13]. These PGPR invade plant rhizospheres/endo-rhizospheres and stimulate plant development by one or more direct and/or indirect methods [14-17]. In addition, the relevance of PGPR for the control of biotic and abiotic stressors is growing. The mechanism of drought tolerance and its mitigation for plants by rhizobacteria might be a collective outcome of several activities including (i) the synthesis of phytohormones such as indole-3-acetic acid (IAA), abscisic acid (ABA), gibberellic acid, and cytokinins; (ii) production of ACC deaminase decreasing the ethylene levels in roots; (iii) by releasing exopolysaccharides; and (iv) induction of systemic tolerance to diseases by bacterial compounds [18]. Recently, PGPR were found to contribute to plant abiotic stress management $[2,19]$. Many recent studies have demonstrated the importance of PGPR, such as Ochrobactrum sp. [20] and Pseudomonas pseudoalcaligenes [21], for the amelioration of drought stress in edible crops. For example, when drought-tolerant PGPR strains were administered as soil inoculants to maize plants grown in a water deficit environment, they significantly improved the growth, root elongation, and NPK uptake by reducing ethylene levels in plants [22]. Similarly, root and shoot lengths, stem diameters, dry biomass, and chlorophyll contents of bean plants cultivated in drought-stressed soils were augmented following the application of the drought-tolerant PGPR strain Rhodobacter sphaeroides KE149 [23].

By affecting the biochemical (antioxidative defense system) and physiological (photosynthetic attributes) systems, drought-tolerant PGPR protect crops from abiotic stress [24,25]. In the present study, the drought-tolerant PGPR strain Enterobacter sp./L. adecarboxylata PAB19 was isolated from rhizosphere soil, characterized and applied to $V$. radiata, considering its ability to endure water stress and to produce multiple bioactive metabolites including IAA, ACC deaminase, siderophores, and ammonia. Additionally, the biofilm-forming ability of the strain was assessed. The abilities of PGPR to synthesize growth-regulating substances and form biofilms are believed to protect microbial cells from stress and help them withstand constantly changing environmental conditions in the rhizosphere. Despite their global importance, firm data on the effect of water stress on legumes, especially $V$. 
radiata is scarce. Therefore, our goals were: (i) to isolate and identify drought-tolerant PGPR strains with multiple PGP features (this led to the selection of strain PAB19); (ii) to assess the effect of PEG-6000 (most effective water-repellent agents) on plant growth regulating substances in strain PAB19; (iii) to evaluate the mitigation potential of PAB19 on growth, dry biomass, leaf pigments, and nutrient uptake of $V$. radiata cultivated under water deficit conditions; (iv) to determine the effects of PAB19 on rhizobia- $V$. radiata symbiosis and seed attributes; (v) to assess stress markers and antioxidant response in inoculated plants raised under water deficit conditions; and (vi) to evaluate the effects of PAB19 on leaf exchange parameters of treated and untreated $V$. radiata plants.

\section{Material and Methods}

\subsection{Isolation and Biochemical Characterization of Bacterial Isolates}

To isolate PGPR, soil samples were collected from the rhizosphere region of fields cultivating vegetables from the agricultural fields of Faculty of Agricultural Sciences, Aligarh Muslim University, Aligarh, India (coordinates: 27.92249, 78.07141). The soils were serially diluted and $100 \mu \mathrm{L}$ aliquots were spread plated on Pikovskaya (PVK) agar ( $\mathrm{g} \mathrm{L}^{-1}$ : glucose 10; $\mathrm{Ca}_{3}\left(\mathrm{PO}_{4}\right)_{2}$; $\left(\mathrm{NH}_{4}\right)_{2} \mathrm{SO}_{4} 0.5 ; \mathrm{NaCl} 0.2 ; \mathrm{MgSO}_{4} \cdot 7 \mathrm{H}_{2} \mathrm{O} 0.1 ; \mathrm{KCl} 0.1 ;$ yeast extract 0.5; $\mathrm{MnSO}_{4}$ and $\mathrm{FeSO}_{4}$ trace; agar 15; pH 7.0) medium. Plates were incubated for $4-5$ days at $28 \pm 2{ }^{\circ} \mathrm{C}$. Colonies with various zones of solubilization (halo zones) around bacterial growth were purified three times on the same medium. These isolates were subsequently examined by Gram's staining and biochemically and morphologically characterized following earlier described methods [26]. Starch and gelatin hydrolysis by isolates were also evaluated [26].

\subsection{Drought Tolerance Assay of Bacterial Isolates}

To assess the water stress tolerance of isolated PGPR strains, we used minimum inhibitory concentrations (MICs) against polyethylene glycol (PEG-6000) (Himedia, Pvt., Ltd., Mumbai, India). Briefly, PEG amended (0-20\%) PKV agar plates were prepared and spot inoculated with $10 \mu \mathrm{L}$ of freshly grown cultures. Plates were incubated at $28 \pm 2{ }^{\circ} \mathrm{C}$ for two days and growth was recorded.

\subsection{Molecular Characterization of Strain PAB19}

After morphological and biochemical characterization and determining its tolerance to abiotic stress (PEG), a region of the gene encoding the 16S rRNA of the strain PAB19 was amplified by PCR and sequenced using a commercially available service provided by Macrogen, Seoul, South Korea (refer to Section S2.3). A phylogenetic tree was constructed in order to identify strain PAB19.

2.4. Plant Growth Regulating (PGR) Substance Release by Enterobacter sp./L. adecarboxylata PAB19 under Different Levels of Water Stress

\subsubsection{Quantification of Indole-3-acetic Acid (IAA)}

The IAA synthesized by PAB19 was quantitatively evaluated as described by Bric et al. [27]. For this assessment, PAB19 was cultured in Luria Bertani (LB) broth (HiMedia Pvt. Ltd., Mumbai, India) containing a fixed concentration $(100 \mu \mathrm{g} / \mathrm{mL})$ of tryptophan and various concentrations of PEG-6000 (0-15\%). The culture was incubated at $28 \pm 2{ }^{\circ} \mathrm{C}$ at $125 \mathrm{rpm}$ for 2-3 days. After completion of incubation, $5.0 \mathrm{~mL}$ of culture was centrifuged at $10,000 \times g$ for $20 \mathrm{~min}$ and $2.0 \mathrm{~mL}$ of supernatant was mixed with $4.0 \mathrm{~mL}$ of Salkowski reagent and few drops of orthophosphoric acid were added. After adding these reagents, tubes were kept for $30 \mathrm{~min}$ in darkness. The absorbance of the pink solution was read at $530 \mathrm{~nm}$ using UV-Vis spectrophotometer (UV-2450, Shimadzu, Tokyo, Japan).

\subsubsection{Bioassay of Siderophore Production}

The PGPR isolates were spot inoculated on 0-15\% PEG supplemented universal chrome azurol S (CAS) agar plates and then siderophore production was investigated as 
previously described [28,29]. Furthermore, phenolate siderophore (SA and 2,3-DHBA) synthesized by strain PAB19 in the absence or presence of different levels of the drought was estimated following the method of Reeves et al. (1983) (refer to Section S2.4.2).

\subsubsection{ACC Deaminase Activity}

The ACC deaminase activity of strain PAB19 was assessed by culturing bacterial cells in a liquid medium supplemented with different concentrations $(0-15 \%)$ of PEG solution [30,31] (refer to Section S2.4.3).

\subsubsection{P-Solubilization and $\mathrm{NH}_{3}$ Production}

The P-solubilization ability of PAB19 was examined quantitatively by growing the bacterium in Pikovskaya's broth containing different concentrations of PEG-6000 [32]. After inoculation, flasks were incubated at $30 \pm 2{ }^{\circ} \mathrm{C}$ for seven days on a rotary shaker at $120 \mathrm{rpm}$. The quantity of solubilized $\mathrm{P}$ as a result of bacterial activity was measured using chlorostannous-reduced molybdo-phosphoric acid after removing $10 \mathrm{~mL}$ of culture broth from each flask and centrifuged at $5724 \times g$ for $30 \mathrm{~min}$. A volume of $100 \mu \mathrm{L}$ of chlorostannous acid was added to $10 \mathrm{~mL}$ supernatant, and the content was adjusted to $50 \mathrm{~mL}$ with distilled water. The blue colour developed was read at $600 \mathrm{~nm}$ on UV-visible spectrophotometer. Using the potassium dihydrogen phosphate $\left(\mathrm{KH}_{2} \mathrm{PO}_{4}\right)$ calibration curve, the amount of P-solubilized was determined. Hydrogen cyanide and ammonia synthesis by PAB19 were assayed following the methods described by Bakker and Schippers [33] and Dye [34], respectively.

\subsection{Assessment of Biofilm Development and Associated Traits by PAB19 under Water Stress}

The development of biofilms on 96 well-plates by PAB19 in the absence/presence of PEG was assessed using 1\% crystal violet (CV) as previously described [35] (refer to Section S2.5). Extracellular polymeric substances (EPS) produced by the strain in the presence of water stress were estimated as described by Mody et al. [36]. Alginate produced by strain PAB19 was also assayed. For this assay, cells were grown in a liquid medium containing different concentrations of PEG (Section S2.5). Similarly, the cell surface hydrophobicity (CSH) of PAB19 was quantified by cultivating cells with/without added PEG using the bacterial adhesion to hydrocarbons (BATH) method previously described by Rosenberg [37].

\subsection{Plant Experiments}

\subsubsection{Bacterial Inoculation, Plant Culture, and Seed Treatment}

Seeds of $V$. radiata (L.) R. Wilczek were procured from a local market, surface sterilized with $3 \%$ sodium hypochlorite $(\mathrm{NaOCl})$, washed thrice, and dried at room temperature. Bacterial coating of seeds was performed using freshly prepared inoculums of $\sim 1 \times 10^{9}$ cells. Polyethylene glycol (PEG-6000) solutions were prepared at 2, 5, 10, or 15\% in doubledistilled water (DDW) and applied to make the soil wet at least one day before sowing. Treated soils ( $5 \mathrm{~kg}$ per earthen pot; $20 \times 24 \mathrm{~cm}$ in diameter) were prepared. The pots were set up in a random block configuration and the experiment was performed in triplicate. Seedlings were thinned after germination, and two healthy $V$. radiata seedlings of similar lengths were cultivated in each pot for 15 days after emergence (DAE). The pots were watered regularly and kept in an open field environment ( $\sim \mathrm{h}$ light $/ \sim 15 \mathrm{~h}$ dark). To ensure the consistency of our findings, crop trials were also repeated in the consecutive year under similar environmental conditions.

2.6.2. Germination Efficiency, Vigor Indices, Leaf Water Potential, and Membrane Stability Indices

Seed Germination Efficiencies and Seedling Vigor Indices (SVIs)

Surface sterilized ( $3 \% \mathrm{NaOCl}, 10 \mathrm{~min})$ seeds of $V$. radiata were coated with Enterobacter sp./L. adecarboxylata $\left(\sim 1 \times 10^{9}\right.$ cells $)$ and sown in earthen pots containing $5.0 \mathrm{~kg}$ soils 
pre-treated with different concentrations of stressor, i.e., PEG-6000. Six days after sowing (DAS), the seed germination efficiency was recorded. Seed germination efficiencies (\%) were calculated as follows:

$$
\text { Germination } \%=\frac{\text { Number of germinated seeds }}{\text { Total number of seeds }} \times 100
$$

SVI were calculated using the following formula:

$$
\text { SVI }=[\text { Root length }+ \text { Shoot length }] \times \% \text { Seed Germination }
$$

Leaf Water Potential ( $\Psi \mathrm{L})$ Assessment

The $\Psi \mathrm{L}$ of the youngest fully expanded leaves of PEG-treated and strain PAB19 inoculated $V$. radiata plants were estimated using a pressure chamber (model 615, PMS Instruments, Albany, OR, USA).

Membrane Stability Index (MSI)

The MSI of $V$. radiata plants grown on PEG-treated soils and inoculated with strain PAB19 was determined. For the assay, 0.1 gm leaf samples were placed in glass vials containing $10 \mathrm{~mL}$ of DDW and then placed in a water bath at $40^{\circ} \mathrm{C}$ for $30 \mathrm{~min}$. Initial conductivity (C1) was measured using an electrical conductivity meter after cooling to $25^{\circ} \mathrm{C}$ (Model 335 D, Systronics, Ahmedabad, Gujarat, India). Leaf samples were then placed in a water bath for $10 \mathrm{~min}$ at $100^{\circ} \mathrm{C}$, cooled to room temperature, and final conductivity (C2) was measured. MSIs were calculated as follows:

$$
\text { MSI }=[1-(\mathrm{C} 1 / \mathrm{C} 2)] \times 100
$$

2.6.3. Assessments of $V$. radiata Growth and Dry Biomass under Varying Levels of Water Stress

At 50 and 80 DAS, V. radiata plants inoculated with drought-tolerant Enterobacter sp./L. adecarboxylata PAB19 and cultivated in soils at different levels of water stress were detached, germination percentages, root and shoot lengths and dry biomasses, were determined.

\subsubsection{Photosynthetic Pigments, Nutrient Uptakes, Symbiosis, and Yields}

Leaf pigments ( $\mathrm{Chl} \mathrm{a}, \mathrm{Chl} b$, total chlorophyll, and carotenoid) in the foliage of strain PAB19 inoculated and PEG-treated $V$. radiata were extracted and quantified $[38,39]$ (refer to Section S2.6.4). Nutrient (N and P) uptake by PGPR inoculated and PEG-treated $V$. radiata were analyzed as described by Jackson et al. [40] and Lindner et al. [41], respectively. For estimation of $\mathrm{N}$ content, a $10 \mathrm{~mL}$ aliquot of digested roots and shoots samples were taken in a $50 \mathrm{~mL}$ volumetric flask. To this, $2.0 \mathrm{~mL}$ of $2.5 \mathrm{~N}$ sodium hydroxide $(\mathrm{NaOH})$ and $1.0 \mathrm{~mL}$ of $10 \%$ sodium silicate solution were added to neutralize the access of acidity and to prevent turbidity, respectively. The volumetric flask was filled up to the mark of $50 \mathrm{~mL}$ by DDW. In a $10 \mathrm{~mL}$ graduated test tube, $5.0 \mathrm{~mL}$ aliquot of this solution was taken, and $0.5 \mathrm{~mL}$ Nessler's reagent was added allowed to stand for $5 \mathrm{~min}$ for color development. The absorbance was read at $525 \mathrm{~nm}$ and $\mathrm{N}$ content was calculated using the standard curve. For $\mathrm{P}$ estimation, one gram of dried samples was digested in nitric acid and perchloric acid prepared in a ratio of 4:1. Then, $5.0 \mathrm{~mL}$ of acid digested sample was mixed with $5.0 \mathrm{~mL}$ of vanadomolybdate reagent. The volume was made to $25 \mathrm{~mL}$ with DDW. The solution was incubated for $30 \mathrm{~min}$ until the formation of yellow color. Absorbance was measured at $470 \mathrm{~nm}$.

Enterobacter sp./L. adecarboxylata inoculated and PEG-treated roots of $V$. radiata were carefully detached and nodules were removed, counted, and oven-dried for $48 \mathrm{~h}$ at $80^{\circ} \mathrm{C}$. Dry biomasses of nodules (mg plant ${ }^{-1}$ ) were then determined. Concentrations of leghemoglobin $(\mathrm{LHb})$ in root nodules were measured quantitatively, as previously described [25]. Seed yields (pod number, pod biomass, seed number, and seed biomass) were also measured. Lowry's method was used to extract and estimate the grain protein [42]. 
2.6.5. Effects of Enterobacter sp./L. adecarboxylata on Stress Biomarkers and Antioxidant-defense Enzymes in V. radiata Grown under Conditions of Water Deficit Proline Estimation

Proline contents in leaf tissues of PGPR inoculated and PEG-treated $V$. radiata were measured as previously described by [43] (refer to Section S2.6.5.1.1).

Estimation of Thiobarbituric Acid Reactive Substances (TBARS)

Malondialdehyde contents in PAB19 inoculated and PEG-treated leaf tissues of $V$. radiata were measured as described by [44] (refer to Section S2.6.5.1.2).

\subsubsection{Determination of Antioxidant Enzymes}

Antioxidant enzyme activity was measured in PGPR inoculated and PEG-treated foliage of $V$. radiata. Catalase (CAT), superoxide dismutase (SOD), peroxidase (POD), and glutathione reductase (GR) activities were measured as described by Beers and Sizer [45], Beauchamp and Fridovich [46], and method-1 described by Jablonski and Anderson [47], respectively (refer to Section S2.6.6).

2.6.7. Gas-Exchange Parameters of V. radiata Plants Inoculated with PAB19 Strain and Exposed to Varying Levels of Water Stress

The gas exchange parameters of strain PAB19 inoculated and PEG-treated V. radiata foliage were also evaluated. Stomatal conductance $(g s)$, rate of transpiration $€$, internal $\mathrm{CO}_{2}$ concentration $\left(C_{\mathrm{i}}\right)$, net photosynthetic rate $\left(P_{\mathrm{N}}\right)$, and vapor pressure deficit $(\mathrm{kPa})$ were measured using a Li-COR 6400 portable photosynthesis system (Li-COR, Lincoln, NE, USA).

\subsection{Rhizosphere/Rhizoplane Colonization by Enterobacter sp./L. Adecarboxylata under Water Stress}

Rhizosphere and rhizoplane colonization by strain PAB19 were determined as described by Shahid et al. [43] (refer to Section S2.7).

\subsection{Statistical Analyses}

The experiments were performed for two consecutive years under similar experimental conditions and plants were subjected to identical treatments. Each experiment was conducted three times in triplicate. Results are presented as means \pm SDs of replicates. Analysis of variance (ANOVA) was performed using the Minitab 17 software package. Dun'an's Multiple Range Test (DMRT) was used to examine the significance of differences between treatments using a two-way analysis of variance and a significance level of $5 \%$.

\section{Results and Discussion}

\subsection{Bacterial Variables: Morpho-Biochemical and PGP Traits, Water Stress Tolerance, and $16 S$} rRNA Based Analysis

Globally, drought stress poses a major challenge to agro-sustainability and often results in compromised plant growth, low nutrient uptake, reduced photosynthesis, and disrupted physiological processes. To address this problem, we isolated a drought-tolerant PGPR that could be used as a microbial resource to improve the performance and productivity of crops in water-stressed environments. In this study, a total of 20 rhizospheric isolates were collected and examined for their morphological and biochemical characteristics. All strains were detected under a light microscope as red/pink Gram-negative short rods but each one showing varied responses to biochemical tests. Furthermore, all PGPR isolates were assessed for their efficiency to produce plant growth-promoting substances. Isolates showed a varied level of IAA production when cultured in LB medium supplemented with different concentrations of tryptophan. Generally, the highest production of IAA occurred at $400 \mu \mathrm{g} \mathrm{mL} \mathrm{m}^{-1}$ of tryptophan. For instance, isolate PAB19 produced the maximum amount of IAA (231 $\mu \mathrm{g} \mathrm{mL} \mathrm{mL}^{-1}$ IAA) at $400 \mu \mathrm{g} \mathrm{mL}^{-1}$ of tryptophan (Table 1). Similarly, bacterial isolates showed variable ACC deaminase activity when grown on DF salt medium 
supplemented with $3.0 \mathrm{mM}$ ACC instead of $\left(\mathrm{NH}_{4}\right)_{2} \mathrm{SO}_{4}$. Here, bacterial ACC deaminase activity ranged between $13.2 \mu \mathrm{M} \alpha$ - ketobutyrate $\mathrm{mg}^{-1}$ protein hour ${ }^{-1}$ (PAB7) to $29.3 \mu \mathrm{M} \alpha$ ketobutyrate $\mathrm{mg}^{-1}$ protein hour ${ }^{-1}$ (PAB19). In the liquid culture medium, PAB19 exhibited the maximum solubilization of TCP $\left(68.3 \mu \mathrm{g} \mathrm{mL}^{-1}\right)$. The isolated bacterial strains were checked further to assess the production of $\mathrm{NH}_{3}$ and siderophore by growing them in peptone water and nutrient broth medium, respectively. All the isolates showed a positive response to siderophore and ammonia production (Table 1). Among the PGPR isolates, strain PAB19 tolerated an exceptionally higher level of water stress (15\% PEG-6000) when cultured on PEG supplemented agar plates (Table 1). Based on its drought tolerance profile, strain PAB19 was selected for inoculation in crop studies. Strain PAB19 exhibited positive reaction for citrate utilization, nitrate reduction, starch, and gelatin hydrolysis, and catalase and peroxidase activity. Based on its biochemical and cultural properties, PAB19 belonged to the genus Leclercia and the $16 \mathrm{~S}$ rRNA gene sequencing identified it at the species level as Enterobacter sp./L. adecarboxylata. The 16S rRNA nucleotide sequence of strain PAB19 (564 bp) was deposited to GenBank (Accession Number MT672579.1). A similarity search using BLASTn software revealed that strain PAB19 was closely related to Enterobacter sp./L. adecarboxylata (99.64\% sequence identity), which indicated strain PAB19 as Enterobacter sp./L. adecarboxylata. MEGA 7.0 software was used to create a phylogenetic tree based on a partial 16S rRNA gene sequence (Figure 1) because the 16s rRNA gene sequence analysis is a commonly accepted methodology for bacterial strains identification (at least, at the genus level) $[48,49]$.

Table 1. Plant growth-promoting features of the PGPR isolates (PAB1 to PAB20) recovered from rhizosphere soils and their tolerance to water stress (PEG-6000).

\begin{tabular}{|c|c|c|c|c|c|c|c|c|c|c|}
\hline \multirow{2}{*}{$\begin{array}{l}\text { Bacterial } \\
\text { Isolates }\end{array}$} & \multicolumn{5}{|c|}{ IAA Production $\left(\mu \mathrm{g} \mathrm{mL}^{-1}\right)$} & \multirow{2}{*}{$\begin{array}{c}\text { ACC Deaminase } \\
\text { ( } \mu \text { mol } \alpha-\mathrm{KB} / \mathrm{mg} \\
\text { Protein } / \mathrm{h})\end{array}$} & \multirow{2}{*}{$\begin{array}{c}\mathrm{P}- \\
\begin{array}{c}\text { Solubilization } \\
\left(\mu \mathrm{g} \mathrm{mL}^{-1}\right)\end{array}\end{array}$} & \multirow{2}{*}{$\begin{array}{c}\mathrm{NH}_{3} \\
\text { Production }\end{array}$} & \multirow{2}{*}{$\begin{array}{l}\text { Siderophore } \\
\text { (FeCl }{ }_{3} \text { test) }\end{array}$} & \multirow{2}{*}{$\begin{array}{c}\text { Water Stress Tolerance } \\
\text { to PEG-6000 }\end{array}$} \\
\hline & OT & $100 \mathrm{~T}$ & $200 \mathrm{~T}$ & $300 \mathrm{~T}$ & $400 \mathrm{~T}$ & & & & & \\
\hline PAB1 & 23.2 & 27.2 & 36.7 & 47.1 & 67.2 & 17.5 & 43.7 & ++ & ++ & $5 \%$ \\
\hline PAB2 & 14.3 & 18.0 & 24.3 & 29.5 & 36.1 & 19.3 & 37.8 & + & ++ & $2 \%$ \\
\hline PAB3 & 9.23 & 15.7 & 22.6 & 35.4 & 42.7 & 22.0 & 34.2 & + & ++ & $7 \%$ \\
\hline PAB4 & 11.0 & 18.1 & 26.3 & 37.9 & 52.0 & 21.2 & 45.7 & + & ++ & $8 \%$ \\
\hline PAB5 & 26.8 & 43.2 & 67.6 & 73.2 & 87.1 & 17.4 & 49.0 & ++ & ++ & $5 \%$ \\
\hline PAB6 & 8.9 & 16.8 & 28.7 & 40.1 & 55.0 & 18.4 & 52.5 & ++ & ++ & $9 \%$ \\
\hline PAB7 & 10.8 & 17.4 & 26.0 & 41.4 & 52.7 & 13.2 & 34.1 & ++ & ++ & $10 \%$ \\
\hline PAB8 & 23.7 & 32.8 & 46.8 & 65.9 & 87.4 & 19.3 & 30.9 & ++ & ++ & $12 \%$ \\
\hline PAB9 & 14.3 & 19.3 & 32.1 & 42.5 & 53.1 & 20.3 & 46.2 & ++ & ++ & $5 \%$ \\
\hline PAB10 & 2.6 & 4.8 & 17.3 & 22.7 & 31.2 & 22.5 & 57.3 & ++ & ++ & $7 \%$ \\
\hline PAB11 & 13.2 & 18.0 & 24.6 & 32.1 & 45.7 & 24.2 & 38.2 & + & ++ & $3 \%$ \\
\hline PAB12 & 21.2 & 36.5 & 48.6 & 63.4 & 87.3 & 25.6 & 23.9 & + & ++ & $7 \%$ \\
\hline PAB13 & 12.0 & 16.7 & 28.4 & 35.6 & 43.0 & 23.4 & 28.9 & ++ & ++ & $5 \%$ \\
\hline PAB14 & 34.3 & 44.2 & 56.7 & 89.4 & 112.0 & 25.6 & 55.4 & + & ++ & $5 \%$ \\
\hline PAB15 & 7.8 & 11.9 & 18.5 & 26.4 & 32.4 & 28.1 & 61.7 & + & ++ & $8 \%$ \\
\hline PAB16 & 14.3 & 28.0 & 43.2 & 56.3 & 70.2 & 23.4 & 38.6 & + & ++ & $10 \%$ \\
\hline PAB17 & 11.8 & 16.3 & 23.1 & 32.0 & 47.2 & 28.4 & 43.2 & ++ & ++ & $12 \%$ \\
\hline PAB18 & 6.7 & 17.4 & 22.4 & 28.5 & 38.9 & 24.6 & 56.0 & ++ & ++ & $10 \%$ \\
\hline PAB19 & 89.4 & 136.3 & 165 & 189 & 231 & 29.3 & 68.3 & ++ & ++ & $18 \%$ \\
\hline PAB20 & 21.2 & 39.0 & 75.3 & 84.3 & 92.1 & 25.0 & 49.0 & ++ & ++ & $7 \%$ \\
\hline
\end{tabular}

IAA = indole-3-acetic acid; $\alpha-\mathrm{KB}=\alpha$-keto butyrate; $\mathrm{T}=$ tryptophan; Single ' + ' denotes moderate production while ' ++ ' represents high production. 


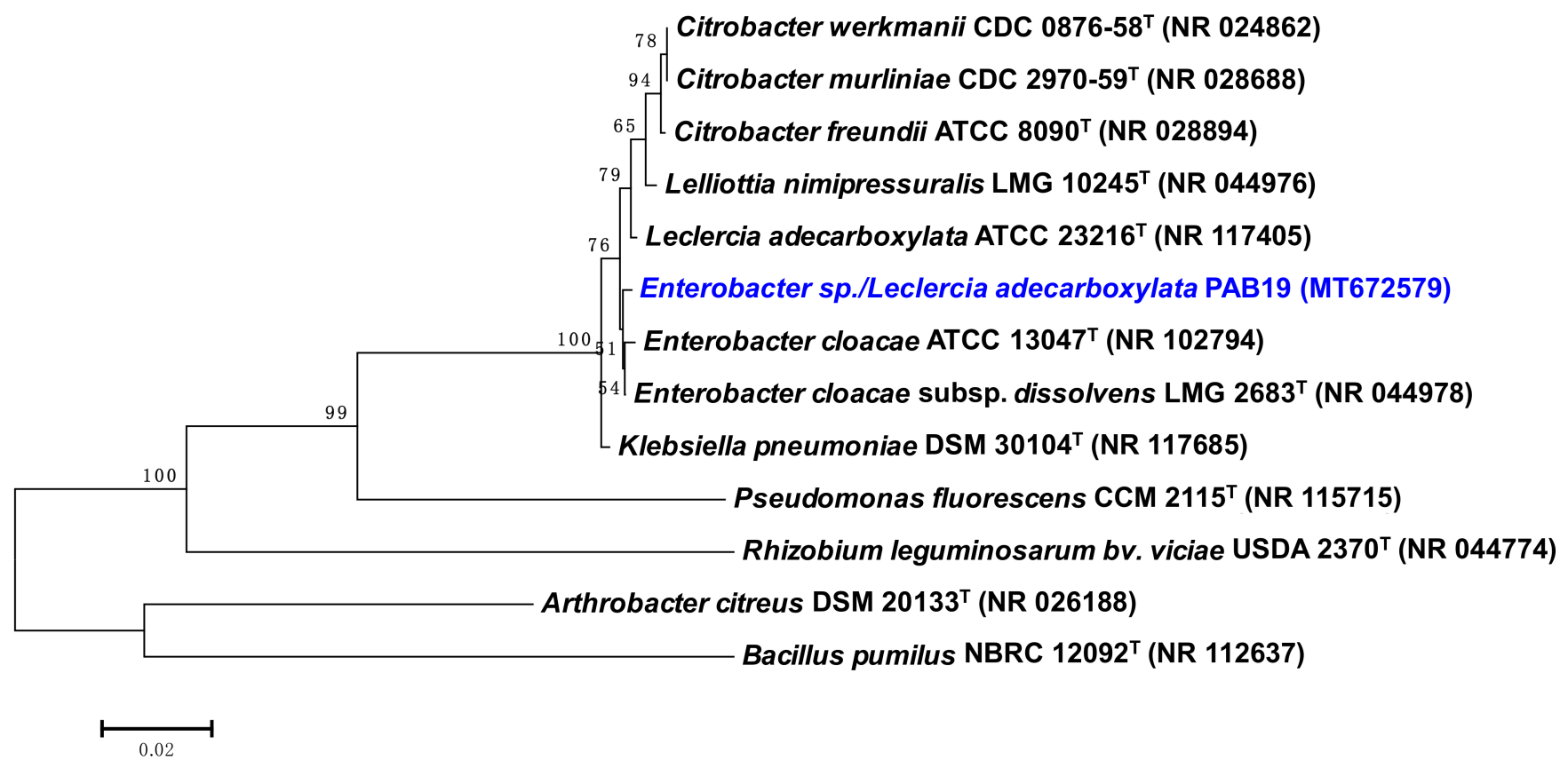

Figure 1. Neighbor-joined phylogenetic tree of Enterobacter sp./Leclercia adecarboxylata PAB19. The tree was constructed based on 16S rRNA partial gene sequences (taken from NCBI BLAST search tool) from some closely related phylogenetic species (type cultures). Sequences were aligned using the Clustal W sequence alignment tool in MEGA 7.0 software. Bootstrap percentage values as obtained from 1000 replications of the data set are given at nodes. The GenBank accession numbers of isolates and other genera or species are presented in parenthesis. The scale bar corresponds to the mean number of nucleotide substitutions per site.

\subsection{Plant Growth-Promoting Features of PAB19 under Water Stress Conditions \\ 3.2.1. Production of Indole-3-acetic Acid and Siderophore}

PGPR strain PAB19 released many active biomolecules when cultivated in a regulated drought-stressed environment (Table 2). Surprisingly, the PGP activities of strain PAB19 increased as water stress increased. The strain PAB19 synthesized $136.3 \pm 6.8 \mu \mathrm{g} \mathrm{mL} \mathrm{mL}^{-1}$ of IAA and this increased with PEG level. For instance, a maximum of $176.2 \pm 5.6 \mu \mathrm{g} \mathrm{mL}^{-1}$ of IAA (a 23\% increase over the non-PEG-treated control) was recorded at a PEG concentration of $15 \%$. It is estimated that approximately $80 \%$ of the rhizospheric bacteria release IAA (a physiologically active auxin) [50], which regulates the growth and various physiological and biochemical processes of plants even under stress (salt, drought, or waterlogging) conditions [51]. Mehmood et al. [52] reported auxin (IAA) promotes root system growth over the long term, which enhances abilities to absorb enough nutrients and water from the soil. In addition, the IAA loosens the plant cell walls leading to enhanced release of root exudates as nutrients for PGPR development [53]. In this regard, various IAA producing drought-tolerant PGPR strains isolated from different ecological niches have been reported to improve the growths of edible crops including legumes. As an example, the inoculation of Rhodobacter sphaeroides KE149, an IAA releasing and drought-tolerant bacterium augmented the growth, biomass, chlorophyll content, and nutritional value of adzuki bean plants [23]. Similarly, Danish et al. [48] reported that the drought-tolerant and IAA-producing PGPR strains P. aeruginosa, E. cloacae, A. xylosoxidans, and L. adecarboxylata in the presence of biochar increased the overall plant physiology. Additionally, growth, nodulation, physiological traits and water tolerance efficiency of soybean plants were enhanced when inoculated with auxin and gibberellin-secreting and drought tolerating rhizobacterium P. putida H-2-3 as reported by Sang-Mo et al. [54]. 
Table 2. Quantification of PGP substances or activity of Enterobacter sp./L. adecarboxylata PAB19 grown with 2-15\% PEG-6000 stress.

\begin{tabular}{|c|c|c|c|c|c|c|c|c|c|}
\hline \multirow[b]{2}{*}{ Treatment } & \multirow[b]{2}{*}{$\begin{array}{l}\text { Dose Rate } \\
\quad(\%)\end{array}$} & \multirow{2}{*}{$\begin{array}{c}\text { IAA } \\
\text { Production } \\
\left(\mu \mathrm{g} \mathrm{mL}^{-1}\right)\end{array}$} & \multirow{2}{*}{$\begin{array}{c}\text { ACC Deaminase } \\
(\mu \mathrm{mol} \alpha-\mathrm{KB} / \mathrm{mg} \\
\text { Protein } / \mathrm{h})\end{array}$} & \multirow[b]{2}{*}{$\begin{array}{l}\text { P-Solubilization } \\
\quad\left(\mu \mathrm{g} \mathrm{mL}^{-1}\right)\end{array}$} & \multicolumn{5}{|c|}{ Production of Siderophore Production } \\
\hline & & & & & $\mathrm{HCN}$ & $\mathrm{NH}_{3}$ & $\begin{array}{c}\mathrm{FeCl}_{3} \\
\text { Test }\end{array}$ & $\begin{array}{c}\mathrm{SA} \\
\left(\mu \mathrm{g} \mathrm{mL}^{-1}\right)\end{array}$ & $\begin{array}{l}\text { 2,3 DHBA } \\
\left(\mu \mathrm{g} \mathrm{mL}^{-1}\right)\end{array}$ \\
\hline \multirow{5}{*}{$\begin{array}{c}\text { Drought } \\
\text { (PEG-6000) }\end{array}$} & 0 & $136.3^{d} \pm 6.8$ & $29.3^{d} \pm 2.5$ & $68.3^{\mathrm{e}} \pm 3.5$ & - & +++ & ++ & $24.2^{\mathrm{e}} \pm 1.4$ & $34.1^{\mathrm{d}} \pm 0.5$ \\
\hline & 2 & $139^{\mathrm{d}} \pm 10.3$ & $31.0^{\mathrm{d}} \pm 7.0$ & $74.6^{\mathrm{d}} \pm 3.0$ & - & ++ & ++ & $27.3^{d} \pm 2.1$ & $36.0^{\mathrm{c}} \pm 1.1$ \\
\hline & 5 & $157.6^{c} \pm 8.5$ & $37.0^{c} \pm 2.0$ & $81.6^{c} \pm 3.2$ & - & ++ & ++ & $31.5^{c} \pm 2.5$ & $38.5^{b} \pm 1.7$ \\
\hline & 10 & $169.6^{b} \pm 5.5$ & $44.0^{\mathrm{b}} \pm 2.0$ & $91.6^{\mathrm{b}} \pm 3.5$ & - & ++ & ++ & $37.0^{\mathrm{b}} \pm 2.8$ & $40.0^{\mathrm{b}} \pm 1.8$ \\
\hline & 15 & $176.2^{\mathrm{a}} \pm 5.6$ & $56.6^{\mathrm{a}} \pm 5.0$ & $98.3^{a} \pm 3.5$ & - & + & ++ & $42.5^{\mathrm{a}} \pm 3.0$ & $44.3^{\mathrm{a}} \pm 2.3$ \\
\hline
\end{tabular}

IAA = indole-3-acetic acid; $\alpha$-KB = $\alpha$-keto butyrate; $\mathrm{HCN}=$ hydrogen cyanide; $\mathrm{SA}=$ salicylic acid; 2,3 DHBA = 2, 3-dihydroxybenzoic acid. ' + ' and ' - ' represent positive and negative reactions, respectively. Values are the mean of three independent replicates. Mean values denoted with different letters are significantly different $(p \leq 0.05)$ as determined by the DMRT test. Values represent means \pm SDs. ' $+{ }^{\prime}, '++{ }^{\prime}$, and ' +++ ' denote low, moderate, and high production, respectively.

Under Fe-deficient conditions, siderophores, low molecular weight Fe (iron) chelating compounds produced by some soil microbes, deliver Fe to plants [55]. Here, we have assessed the bacterial production of phenolate siderophore (salicylic acid and 2, 3-dihydroxy benzoic acid) in the presence of a stressor (PEG-6000). Although salicylic acid (SA) is produced by several bacterial genera, when they grow in iron starvation suggesting that it could act as a siderophore, and its production is generally associated with biosynthesis of small ferric-ion-chelating molecules [56], however some studies do not agree with this fact [57]. Like IAA, siderophore production by PAB19 is also elevated at higher PEG levels. Even at a higher level of drought stress (15\% PEG), strain PAB19 exhibited the production of siderophore. In the current study, PAB19 synthesized $24.2 \pm 1.4 \mu \mathrm{g} \mathrm{mL}^{-1}$ of salicylic acid in the absence of PEG, while $42.5 \pm 3.0 \mu \mathrm{g} \mathrm{mL}^{-1}$ was produced at a PEG concentration of $15 \%$ (Table 2). Likewise, the maximum amount of 2, 3-DHBA $\left(44.3 \pm 2.3 \mu \mathrm{g} \mathrm{mL}^{-1}\right)$ was produced at higher water stress (15\% PEG-6000). Microbially produced siderophore usually aids microbial growth in iron-restricted environments. B. subtilis strain CAS15 produced a siderophore that protected pepper plants from Fusarium wilt (F. oxysporum Schl. f.sp. capsici) [58], and two siderophore-producing strains of B. amyloliquefaciens eliminated Ralstonia solanacearum-induced bacterial wilt in tomatoes [59]. Likewise, increased siderophore production at even higher levels of water stress has been reported [60,61].

\subsubsection{ACC deaminase Activity}

The plant hormone ethylene endogenously regulates plant homeostasis under stress circumstances, resulting in decreased root and shoot development. ACC deaminase-producing bacteria sequester and break down plant ACC to provide $\mathrm{N}$ and energy. Furthermore, by eliminating ACC, the bacteria mitigate the negative effects of ethylene, alleviating plant stress and boosting plant development (Glick, 2005). Considering these, we assessed the ACC deaminase activity of Enterobacter sp./L. adecarboxylata PAB19 in the presence of drought stress. Strain PAB19 cultivated in the medium supplemented with varying levels of PEG showed a good response to ACC deaminase. Increasing PEG concentration significantly increased $\alpha$-ketobutyrate levels, and a PEG level of 15\%, strain PAB19 produced $56.6 \pm 5.0 \mu \mathrm{M}$ $\alpha$-ketobutyrate $\mathrm{mg}^{-1}$ protein $\mathrm{h}^{-1}$, which was greater than the amount of $29.3 \pm 2.5$ ACC deaminase released at a $0 \%$ PEG concentration (Table 2). As found in the present study, researchers have reported the production of ACC deaminase by a variety of drought-tolerant soil bacteria subjected to water deficit. In line with the inoculation impact of our culture on $V$. radiata, the exogenous expression of ACC deaminase by drought-tolerant and biofilm-forming P. azotoformans FAP5 improved the growth and biochemical attributes of wheat plants raised in soils at different levels of water stress [62]. Similar inoculation impact was reported by Danish et al. [22] where ACC deaminase producing PGPR strains mitigated the adverse effects of drought stress and increased photosynthetic rate, stomatal conductance, and the nutritional value of maize. 


\subsubsection{P-solubilizing Activity, $\mathrm{HCN}$, and $\mathrm{NH}_{3}$ Production}

Phosphorus is one of the most important plant nutrients and is involved in almost all aspects of plant metabolism, including the synthesis of leaf pigments, respiration, and energy transfer [11]. P scarcity always restricts plant growth and metabolism. However, less than $5 \%$ of $\mathrm{P}$ in soil is available for plants [63]. Consequently, to prevent $\mathrm{P}$ deficiency, phosphatic fertilizers are often used. However, because of their high costs and issues associated with hazardous effluents, plant $P$ supply has shifted toward natural renewable supplies. Phosphate-solubilizing microorganisms (PSM) of several genera also provide alternatives to synthetic $P$ fertilizers [64]. In fact, many drought-tolerant soil bacteria such as Pseudomonas [65], Azospirillum [66], Proteus [67], and Bacillus [68] solubilize the soil P under conditions of water stress. In our study, we noticed a similar trend of increased $\mathrm{P}$ solubilization activity by strain PAB19 on increasing PEG concentration. The maximum amount $\left(98.3 \pm 3.5 \mu \mathrm{g} \mathrm{mL}^{-1}\right)$ of solubilized $\mathrm{P}$ was recorded at a high PEG concentration $(15 \%)$, which represented a $30 \%$ increase over the non-treated control $\left(68.3 \pm 3.5 \mu \mathrm{g} \mathrm{mL}^{-1}\right)$ (Table 2). Similarly, several drought-tolerant and P-solubilizing PGPR strains viz., $B$. amyloliquefaciens [69] and Proteus [67] when inoculated into water-stressed soil systems augment the growth of edible crops.

However, PEG concentration did not affect the amount of ammonia produced by the PAB19 strain, whereas several researchers have documented the generation of ammonia by drought-tolerant soil bacteria grown in liquid media supplemented with polyethylene glycol [70-72].

\subsection{Effects of Water Stress on Biofilm Development and Associated Traits}

Biofilm development and EPS synthesis are two additional processes that contribute to drought resistance in drought tolerating PGPR. The colonization of plant roots by a rhizobacterium is the very first step for initiating a successful biofilm. In the soil endosphere, rhizoplane, and rhizosphere, there are diverse types of microorganisms. The root-microbe interaction promotes the growth of both plants and PGPR. As a result of a successful plant-microbe interaction, PGPRs successfully colonize the plant root, proliferate into micro colonies, and/or create biofilm [73,74]. Plant-associated biofilms are extremely capable of shielding the host plant from external stress, lowering microbial competition, and providing protective benefits to the host plant, therefore boosting growth, yield, and crop quality. In plant-associated bacterial biofilms, cells and the EPS produced by the cells in response to environmental stimuli work together to sustain the bacterial establishment. Considering these, we decided to evaluate the effect of different levels of water stress on biofilm formation, adhesion of cells to hydrocarbons, and the motility of strain PAB19 in vitro. We found that bacterial biofilm development was dose-dependently reduced in the presence of water stress; however, PAB19 retained the ability to form biofilms even at a PEG concentration of $15 \%$ (Figure 2A).

In addition, we assessed the impact of water stress on EPS production by PAB19. In non-treated controls, PAB19 produced a considerable amount $\left(455.3 \mu \mathrm{g} \mathrm{mL}{ }^{-1}\right)$ of EPS, but it decreased as water stress was increased (Figure 2B). It has been reported that bacterial productions of EPS and alginate tend to improve survival and enhance the productions of active metabolites under harsh conditions such as drought and salinity [75,76]. In our study, the biofilm of PAB19 and associated traits were decreased gradually in a PEG dose-dependent manner, however, strain PAB19 managed to survive and form biofilm and produced the other associated traits. These results show a different trend when compared to the increasing PGP activities of PAB19 under increasing PEG stress (Table 2). This difference could be due to the mode of living of cells of PAB19, i.e., planktonic for PGP activities and static for biofilm formation, as planktonic cells have more contact with the surrounding nutrients and oxygen and are thus able to take up nutrition and release the waste material easily, which is not feasible in the biofilm mode $[77,78]$. The continuous secretion of EPS by four drought-tolerant PGPR strains in a growth medium supplemented with higher concentrations of PEG was reported by Ghosh et al. [79]. Furthermore, inoculation 
of exopolysaccharide synthesizing PGPR strains viz. P. aeruginosa, Proteus penneri, and Alcaligenes faecalis, enhanced the biomass production, organ lengths, and leaf surface area in maize (Zea mays L.) plants, and the soil moisture content [67].
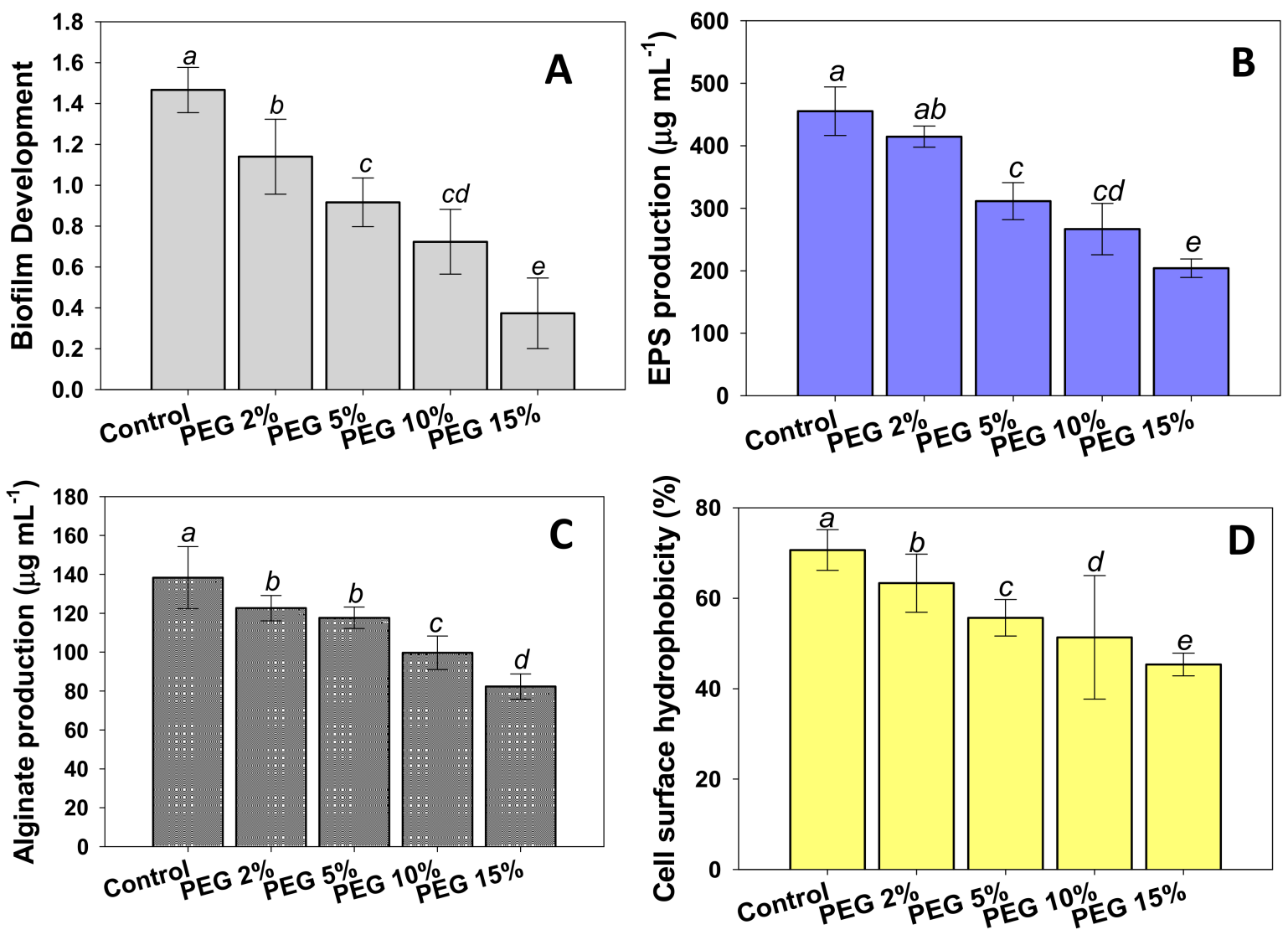

Figure 2. Effects of different levels of water stress (2\%, 5\%, 10\%, and 15\% PEG solution) on biofilm development (A) and their associated traits; EPS production (B), alginate production (C), and cell surface hydrophobicity (D) of Enterobacter sp./L. adecarboxylata PAB 19. In these figures, bar diagrams represent the mean values of three replicates. Mean values followed by different letters were significantly different $(p \leq 0.05)$ as determined by the Duncan's Multiple Range Test (DMRT). Bar and scatter plots represent means \pm SDs.

Like other biofilm traits, the production of alginate by strain PAB19 was diminished by increasing PEG concentrations. Minimum production $\left(82.3 \mu \mathrm{g} \mathrm{mL}^{-1}\right)$ of alginate was recorded at a PEG concentration of $15 \%$ (Figure 2C). Cell surface hydrophobicity (CSH; the adhesion of bacterial cells to hydrocarbons) of strain PAB19 was reduced by increasing the levels of water stress, and PEG at a concentration of $15 \%$ maximally reduced CSH by $36 \%$ versus non-treated controls (70.6\%) (Figure 2D). Bacterial cell surface hydrophobicity is linked to bacterial cell aggregation and adhesion, as well as biofilm formation, and as a result, excessive levels of water stress may impede bacterial colonization behavior [80]. The formation of biofilms and the production of associated traits at high PEG concentrations is a clear indication that the PAB19 strain can withstand severe drought stress, indicating drought tolerance may protect developing bacterial cells and improve survival and activity under water stress.

3.4. Plant-Based Studies: Impact of Enterobacter sp./L. adecarboxylata PAB19 Inoculation on V. radiata Grown in Soil Treated with Different Levels of Water Stress under Pot-House Conditions 3.4.1. Germination Efficiency and Vigor Index

The efficiency of $V$. radiata seed germination in pot soils amended with different doses of PEG and inoculated with PAB19 was recorded at 6 DAS. Almost all seeds planted in untreated soil germinated, whereas PEG at $15 \%$ maximally retarded germination efficiency 
and SVI by 50 and 56\%, respectively, over non-treated controls. However, inoculation of strain PAB19 improved seed germination and the vigor index of $V$. radiata by mitigating water-induced stress (Figure 3A,B). Likewise, the seed germination efficiency of Astragalus caraganae grown under water stress was increased following the inoculation of droughttolerant PGPR strains viz., A. lipoferum, A. chroococcum, P. aeruginosa, and B. cereus [81]. Additionally, the combined inoculation of drought-tolerant species such as Mesorhizobium ciceri, with ACC deaminase positive Bacillus sp. and Pseudomonas strain 6-P, mitigate the drought stress and simultaneously enhance the growth of Cicer arietinum under axenic conditions. It was observed that seedlings with higher osmotic potential (up to 0.4 MPa) had considerably enhanced germination, root and shoot length, and fresh weight compared to non-inoculated control [82].
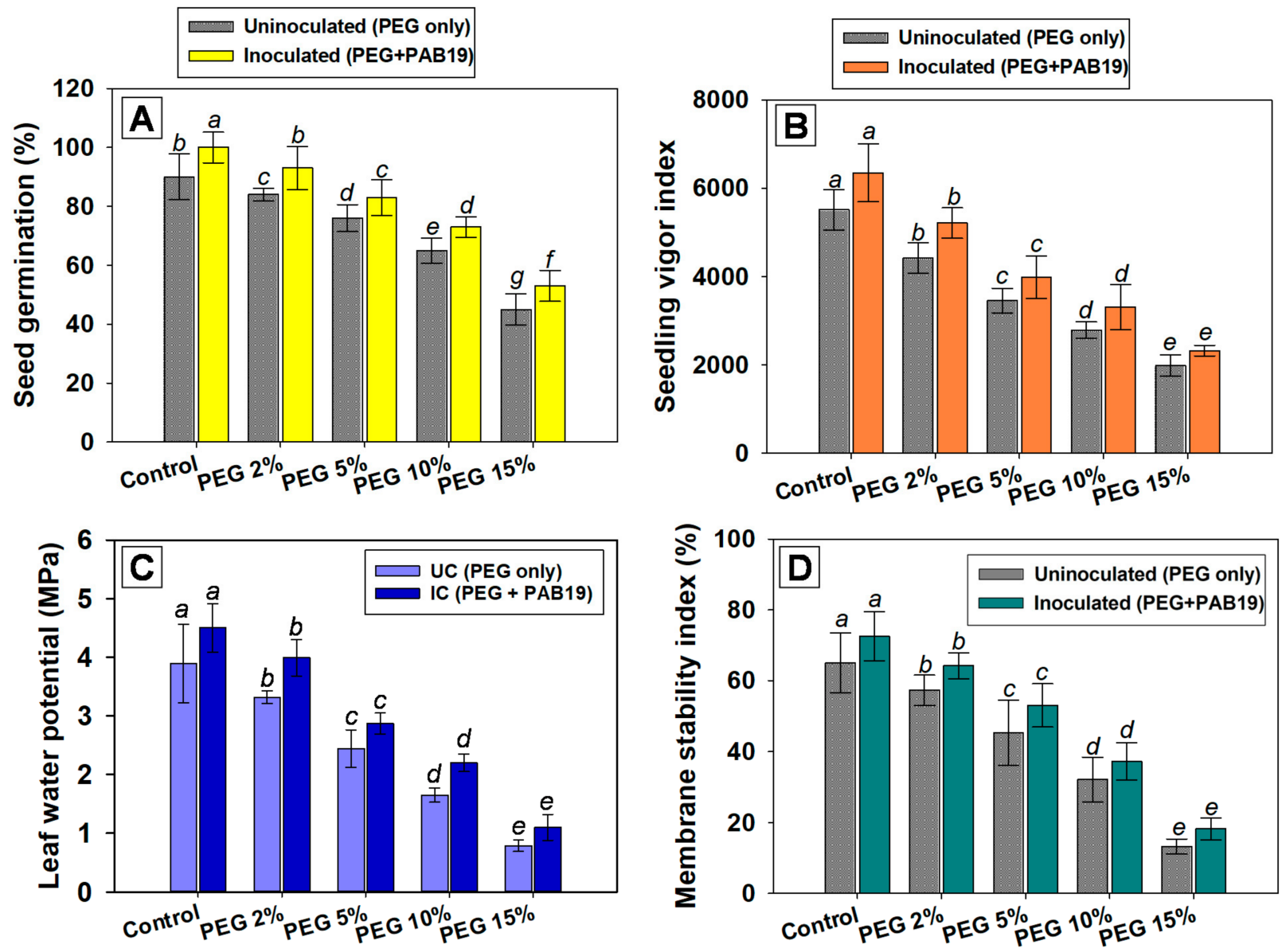

Figure 3. Germination efficiency (A), seed vigor indices (B), leaf water potential (C), and membrane stability indices (D) of V. radiata (L.) cultivated under different levels of water stress (2\%, 5\%, 10\% and 15\% PEG-6000) and inoculated with drought-tolerant Enterobacter sp./L. adecarboxylata PAB19 under green-house conditions. Bar diagrams and curves represent the mean values of experiments done in triplicate. Mean values followed by different letters are significantly different at $p \leq 0.05$ as determined by the DMRT. Bar and scatter plots represent means \pm SDs.

\subsubsection{Effects on Leaf Water Potential and Membrane Stability Index}

The leaf water potential and membrane stability index of strain PAB19 inoculated plants cultivated under water deficit were variable. On increasing PEG concentration, $\Psi \mathrm{L}$ and MSI were significantly $(p \leq 0.05)$ decreased, and $15 \%$ PEG solution had the maximum negative effects and reduced $\Psi \mathrm{L}$ and MSI of $V$. radiata by $79 \%$ and $78 \%$, respectively, versus untreated controls. Similarly, Baroowa et al. [83] reported significant reductions in the $\Psi \mathrm{L}$ and MSI of $V$. radiata under water deficit conditions. However, drought-tolerant Enterobacter sp./L. adecarboxylata mitigated these toxic effects and improved leaf $\Psi \mathrm{L}$ and 
MSI values. For example, in the presence of $2 \%$ PEG, PAB19 maximally increased the $\Psi \mathrm{L}$ and MSI values of $V$. radiata by 18 and $12 \%$, respectively, versus un-inoculated but $2 \%$ PEG-treated plants (Figure 3C,D). These results indicated that inoculation of strain PAB19 had a supporting function in $V$. radiata as the $\Psi \mathrm{L}$ and MSI of plants were improved under drought-challenged circumstances. It also implies that drought-tolerating strain PAB19 hastened the modification of the plant's morphology (growth parameters), as well as leaf water potential (physiological properties) probably by synthesizing the IAA.

\subsection{Growth and Biomass}

PGPR bio-primed and PEG supplemented $V$. radiata raised in pots exhibited variable growth (Figure S1). In general, the growth parameters of plants were decreased on increasing PEG concentration, but plant length and weight were enhanced after inoculating PAB19 (Figure 4A-D). For example, lengths and dry biomasses of roots and shoots were severely reduced by $15 \%$ PEG. On the other hand, these parameters increased in PAB19 inoculated plants, even under water stress. For example, at 2\% PEG, PAB19 maximally increased root and shoots lengths (Figure $4 \mathrm{~A}, \mathrm{~B}$ ) and dry biomasses (Figure $4 \mathrm{E}, \mathrm{F}$ ) by $13 \%$, $9 \%, 12 \%$, and $11 \%$, respectively, as compared with un-inoculated, $2 \%$ PEG-treated plants. A similar pattern was observed for fresh weights of roots and shoots (Figure 4C,D). The effects of PAB19 and PEG were significant $(p \leq 0.05)$ for all measured parameters. These increases even in presence of water stress were probably due to the enhanced production of IAA and other PGP active chemicals, which aid plants by promoting symbiosis and root morphogenesis in the presence of drought stress. Additionally, it was observed that longer roots were produced after inoculation with Enterobacter sp./L. adecarboxylata which may aid in the absorption of comparatively more water from deep soil under drought stress circumstances. The strain PAB19 significantly improved the overall performance of $V$. radiata, and we attributed this to the release of growth-regulating substances [84]. IAA, for example, increases root growth, whereas siderophore, ACC deaminase, HCN, and ammonia are involved in plant development. One of the most significant adaptations of plants to withstand the drought is their root system design. The treatment of drought tolerating PGPR has been shown to increase root development and change root architecture in plants. It has also been suggested that bacterial-induced changes in root architecture might contribute to an increase in total root surface area, therefore enhanced water and nutrient absorption, with favorable consequences for overall plant development [18]. Similarly, several drought-tolerant PGPR strains have been reported to increase the growth and dry biomasses of edible crops, including legumes, cultivated under water stress [85,86]. For instance, Naseem and Bano (2014) used strain Alcaligenes faecalis AF3 with Zea mays seedlings in growth chamber experiments [67]. In that study, drought challenged but PGPR treated plants had a 10\% increase in root length three weeks after planting over drought-stressed but non-inoculated control plants. They claimed that PGPR treatment caused an increase in length and biomass of root resulting in an overall increase in water absorption, allowing treated plants to withstand the drought. 

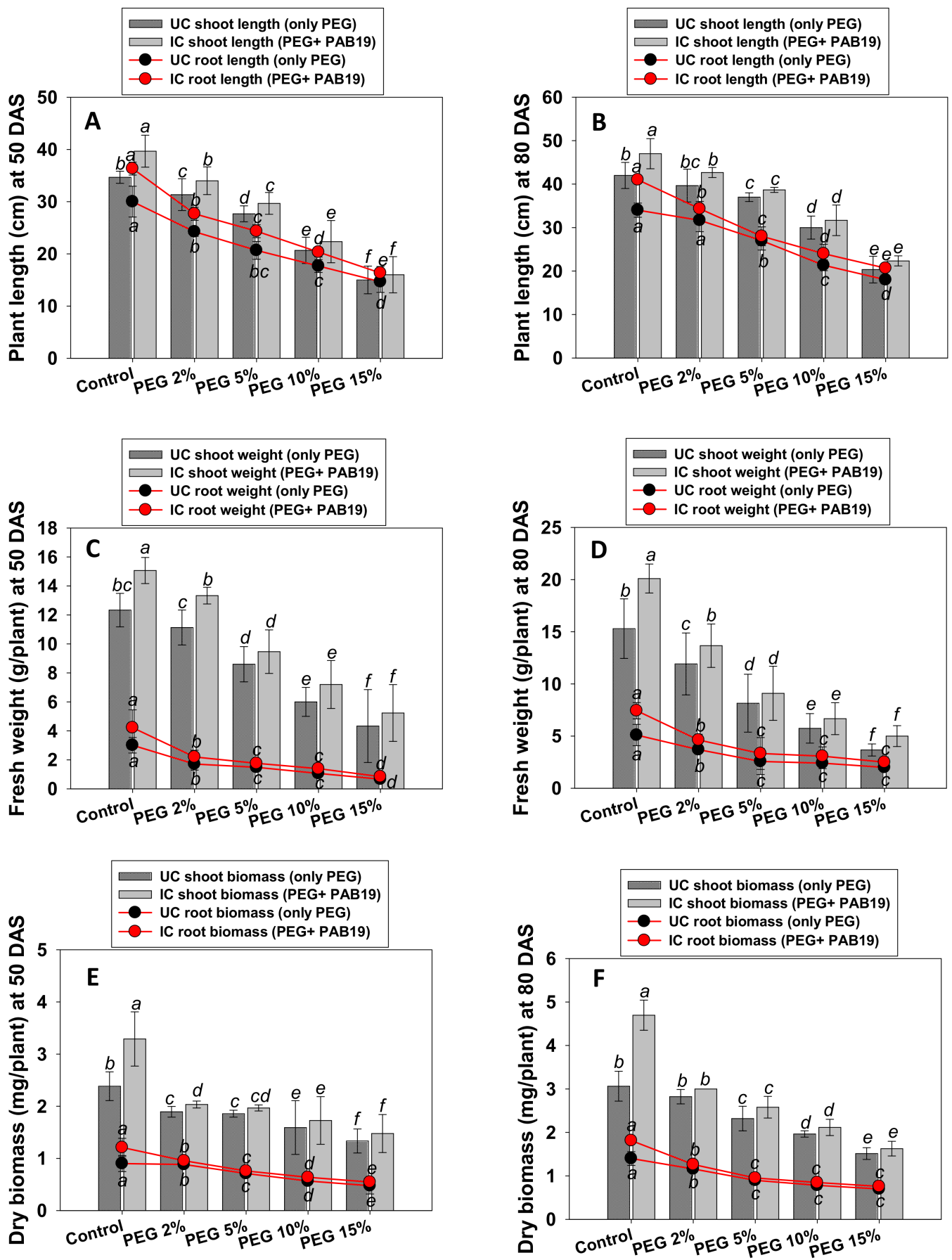

Figure 4. Impact of the bio-inoculation of Enterobacter sp./L. adecarboxylata PAB19 on biological features; plant length at 50 DAS (A) and 80 DAS (B), fresh weight at 50 DAS (C) and 80 DAS (D), dry biomass at 50 DAS (E) and 80 DAS (F) of $V$. radiata (L.) cultivated under different levels of water stress ( $2 \%, 5 \%, 10 \%$ and $15 \%$ PEG-6000) under greenhouse conditions. Bar diagrams represent the mean values of three replicates. Mean values followed by different letters are significantly different $(p \leq 0.05)$ as determined by the DMRT. Bar and scatter plots represent means \pm SDs.

\subsection{Leaf Pigments and Nutrient Uptake}

Photosynthesis is a crucial physicochemical process in higher plants and has a direct influence on biomass production; it is particularly vulnerable to drought. Leaf pigments and symbiotic features of Enterobacter sp./L. adecarboxylata PAB19 and PEG-treated V. radiata plants decreased on increasing water stress. In the current study, drought stress impacts plant photosynthetic properties, which in turn influences the physiological and biochem- 
ical processes, at the whole-plant level. For example, PEG-6000 solution at $15 \%$ greatly diminished chl a, chl b, total chlorophyll, and carotenoid contents by $64 \%, 45 \%, 57 \%$, and $53 \%$, respectively, versus untreated controls. It suggests the loss of photosynthetic pigments by high levels of drought stress that could be due to the increased activity of certain drought-induced enzymes reducing the production of photosynthetic pigments under drought stress. However, PAB19 inoculation of plants raised in soil supplemented with $2 \%$ PEG maximally increased chl-a, chl-b, total chlorophyll, and carotenoid contents by $21 \%, 29 \%, 12 \%$, and $16 \%$, respectively (Figure $5 \mathrm{~A}$ ). The data obtained in the present study suggest that under drought stress, strain PAB19 directly regulates the plant physiology by synthesizing plant hormone (IAA), as well as by improving the mineral and nitrogen availability. The increased photosynthetic pigments by drought-tolerant PGPR in the current study may probably be connected to the development of chloroplast. A similar increase in the formation of photosynthetic pigments in maize plants raised at various levels of water stress was observed after inoculating drought-tolerant PGPR strains, namely, P. aeruginosa, E. cloacae, and L. adecarboxylata [48]. Furthermore, inoculations of B. pumilus and Pseudomonas sp. increased water stress tolerance and increased the chlorophyll levels in maize cultivated under conditions of water deficit [87].

The N and P accumulations in the tissues of PAB19 inoculated and PEG-treated $V$. radiata plants were variable. On increasing water stress, amounts of $\mathrm{N}$ and $\mathrm{P}$ fell significantly $(p \leq 0.05)$. However, after inoculating PAB19, the nutritional contents of $V$. radiata significantly improved. For example, maximum increases in $\operatorname{root} \mathrm{P}$, shoot $\mathrm{P}$, root $\mathrm{N}$, and shoot $\mathrm{N}$ of $10 \%, 11 \%, 23 \%$, and $13 \%$ were recorded when plants were grown in soil treated with 2\% PEG and inoculated with PAB19 (Figure 5B-E). In brief, the analysis showed that inoculation of drought-tolerant PGPR and PEG amended V. radiata plants had considerably higher nutrient content ( $\mathrm{P}$ and $\mathrm{N})$, as compared to controls under water deficit conditions, allowing higher plant performance. This increment in nutrient uptake by plants might be due to the mobilization of various nutrients from the soil to plant root surfaces by soil bacterial activity. Both non-inoculated and PAB19 inoculated plants tend to accumulate more nitrogen in their shoots when subjected to a water shortage. Plant softening increases the concentration of $\mathrm{N}$ in leaves to continue growth in dry conditions. The $\mathrm{P}$ content was greater in un-inoculated and PAB19 inoculated $V$. radiata shoots as compared to the $\mathrm{P}$ content in roots. A similar trend was followed by N. This might be linked to plant's capacity to balance the distribution of nutrients across their compartments as a strategy for responding to environmental changes [88]. In a similar study, improved root growth and enhanced nutrient use efficiency by Zea mays plants grown in soil inoculated with drought-tolerant $P$. fluorescens S3X or Cupriavidus necator 1C2 under water deficit conditions has been reported [89]. In addition, Adesemoye et al. (2008) found that drought-tolerant microbial inoculants improved maize growth as well as $\mathrm{N}$ and $\mathrm{P}$ absorption efficiency [90]. Recently, it was demonstrated that inoculation of beneficial soil bacteria viz., Staphylococcus sciuri, Zobellella denitrificans, and Arthrobacter endophyticus caused an upsurge in nutrient uptake of plants raised in soil showing different levels of drought stress [91]. 

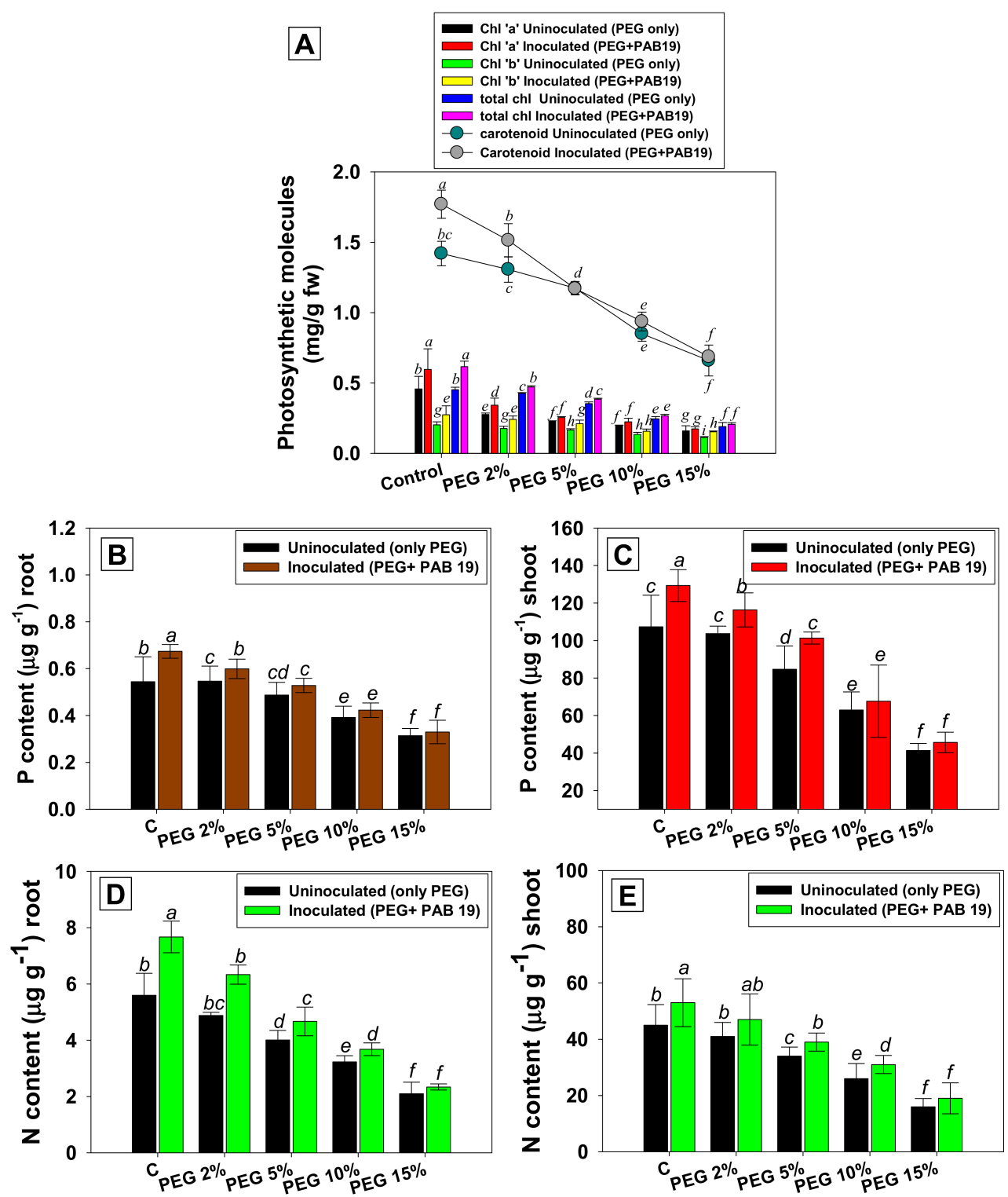

Figure 5. Impacts of the bio-inoculation of Enterobacter sp./L. adecarboxylata PAB19 on leaf pigments (A), shoot P (B), root $\mathrm{P}(\mathrm{C})$, shoot $\mathrm{N}(\mathbf{D})$, and root $\mathrm{N}(\mathrm{E})$ of $V$. radiata $(\mathrm{L}$.) cultivated under different levels of drought stress $(2 \%, 5 \%, 10 \%$ and $15 \%$ PEG-6000) under greenhouse conditions. Mean values followed by different letters are significantly different $(p \leq 0.05)$ as determined by the DMRT test. Bar and scatter plots represent means \pm SDs. Bar and scatter plots represent means \pm SDs.

\subsection{Effect of Enterobacter sp./L. adecarboxylata on Symbiosis and Yield Attributes}

\subsubsection{Nodule Numbers, Biomass, and LHb Contents}

Nodule numbers, dry biomass, and LHb contents of $V$. radiata were maximally reduced by $62 \%, 69 \%$, and $56 \%$, respectively, in the presence of $15 \%$ PEG at 50 DAS (Figure 6). However, inoculation of PAB19 considerably increased these symbiotic features of plants cultivated in water-stressed soils. For example, PAB19 greatly enhanced nodule numbers, biomass, and $\mathrm{LHb}$ content by $10 \%, 38 \%$, and $9 \%$, respectively, in the presence of a $2 \%$ PEG at 50 DAS (Figure 6A-C). Nodule number was found to be strongly correlated with nodule biomass $\mathrm{LHb}$ content $\left(\mathrm{R}^{2}=0.89\right.$ and 0.85 , respectively). The data suggest that PEG-induced decrease in symbiotic efficiency (number, biomass, and $\mathrm{LHb}$ content of nodule) of $V$. radiata was reversed by increased nodulation following the inoculation of drought tolerating, IAA-synthesizing, and other bio-molecule-producing PAB19. It is also suggested that through both local and systemic hormone signaling, successful deployment 
of bacteria in the $V$. radiata rhizosphere enhanced plants' symbiotic attributes. Similarly, in a previous study, drought-tolerant PGPR strains recovered from the root nodules of mung bean improved nodulation, and the symbiotic features of $V$. radiata raised under abiotic stress conditions [92]. Corroborating our results, inoculation of Pisum sativum (pea) plants growing in dried soils with ACC deaminase producing PGPR strain Variovorax paradoxus 5C-2 improved the plant growth [93]. They claimed that bacterized plants showed more seed yield, seed number, and seed nitrogen accumulation and restored nodulation which was repressed in drought stress conditions. Co-inoculation of P. vulgaris L. (common bean) with drought tolerating PGPR strains (Rhizobium tropici CIAT 899, P. polymyxa DSM36, and P. polymyxa Loutit), resulted in higher growth and nodulation relative to plant raised in soil treated only with drought stressor (PEG) [94].
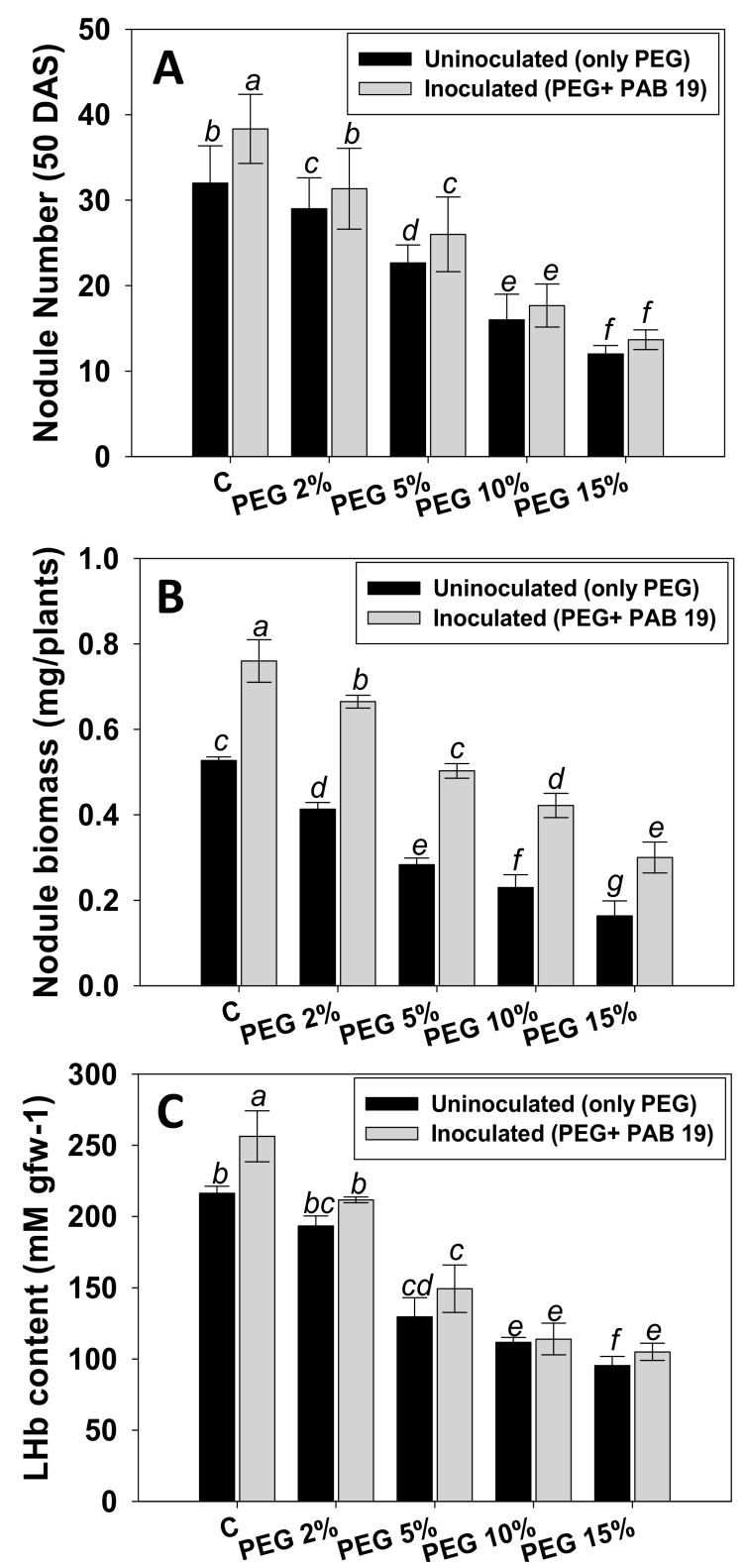

Figure 6. Impact of Enterobacter sp./L. adecarboxylata PAB19 on symbiotic features such as nodule number (A), nodule biomass (B), and LHb content (C) at 50 DAS of $V$. radiata (L.) in the presence of different levels of water stress $(2 \%, 5 \%, 10 \%$ and $15 \%$ PEG-6000) under greenhouse conditions. Bar diagrams represent the mean values of three replicates. Mean values followed by different letters are significantly different $(p \leq 0.05)$ as determined by the DMRT. Bar and scatter plots represent means \pm SDs. 


\subsubsection{Seed Yields}

Seed features of $V$. radiata cultivated in soils at different levels of water deficit exhibited substantial decreases. Maximum decreases in seed parameters were observed at a PEG level of $15 \%$. When PAB19 was administered to V. radiata growing in soil treated with $2 \%$ PEG, pod numbers, yield, seed numbers, seed biomass, and grain protein content rose maximally ( $p \leq 0.05$ ) by $20 \%, 12 \%, 11 \%, 10 \%$, and $10 \%$, respectively (Figure S2A-E). PAB19 and PEG had a significant synergistic effect (bio-inoculum $\times$ PEG) on the yield attributes of $V$. radiata. Plant adaptation is connected with high concentrations of solutes such as soluble carbohydrates and protein to control the osmotic potential of cells, which, in turn, induces an improvement in water absorption under adverse conditions to withstand drought stress. Similarly, drought stress had no influence on growth, seed yield, and ripening of P. sativum in both pot and field studies when ACC deaminase-producing Pseudomonas spp. was used [95]. Furthermore, the application of drought-tolerant PGPR strain V. paradoxus 5C-2 to $P$. sativum plants caused an improved growth, seed yield, and water-use efficiency [96]. Likewise, it has been reported that drought tolerating PGPR strains improved the seed features of wheat crops raised in a water-stressed soil system [97].

\subsection{Impacts of Enterobacter sp./L. adecarboxylata Bio-Inoculation on Stress Markers and} Antioxidant Enzymes in $V$. radiata at Different Levels of Water Stress

\subsubsection{Proline and MDA Contents}

Stress-induced physiological and functional activities can be defined based on accumulations of stressor chemicals (e.g., proline) in plant tissues. In plants, proline (that often acts as an osmolyte) is generated in response to drought stress [98]. Proline synthesis is a frequent response in drought-stressed crops, and it serves to preserve the cell membrane and macromolecule structure throughout stressful conditions. The buildup of proline under stress offers energy for growth and survival, as well as assisting crops in coping with abiotic stressors. Under water stress, proline acts as an osmolyte, accumulating faster and assisting plants in maintaining cell turgor potential [98]. In many plant species, elevated levels of free cellular proteins protect against various biotic and abiotic stressors [99]. In the present study, proline and MDA accumulated in a dose-dependent manner within the fresh foliage of PEG-treated and PAB19 inoculated $V$. radiata, and at a PEG concentration of $15 \%$, shoot proline was maximally induced at $39.6 \mu^{-1} \mathrm{~g}^{-1} \mathrm{fw}(78 \%$ higher versus non-treated controls) and shoot MDA was maximally induced at $29.5 \mu \mathrm{g} \mathrm{g}^{-1} \mathrm{fw}(67 \%$ higher than the control) (Figure 7A,B). However, the presence of drought-tolerant strain PAB19 declined the water stress-induced oxidative stress in $V$. radiata. For example, PAB19 significantly $(p \leq 0.05)$ and maximally lowered shoot proline and MDA levels by $25 \%$ and $20 \%$, respectively, when applied to $V$. radiata plants cultivated in soils containing PEG at $2 \%$. Similarly, two drought-tolerant PGPR strains Bacillus cereus P2 and Planomicrobium chinense P1 reduced proline and malondialdehyde contents when inoculated to Helianthus annus under water-stressed conditions [100], and decreases in proline and MDA contents in foliage were observed in water-stressed chickpea plants inoculated with three droughttolerant PGPR strains, namely, B. subtilis, B. thuringiensis, and B. megaterium [101]. Similarly, three drought-tolerant PGPR, P. jessenii, P. synxantha and A. nitroguajacolicus significantly improved the plant growth by modulating the stress-related enzymes, lowering the level of $\mathrm{H}_{2} \mathrm{O}_{2}$, and malondialdehyde (MDA) content in plants under drought stress relative to non-inoculated plants [102]. These findings support the use of PGPR to improve plant drought tolerance by changing antioxidant activity and stressor metabolites (proline and MDA) in water-stressed situations. 

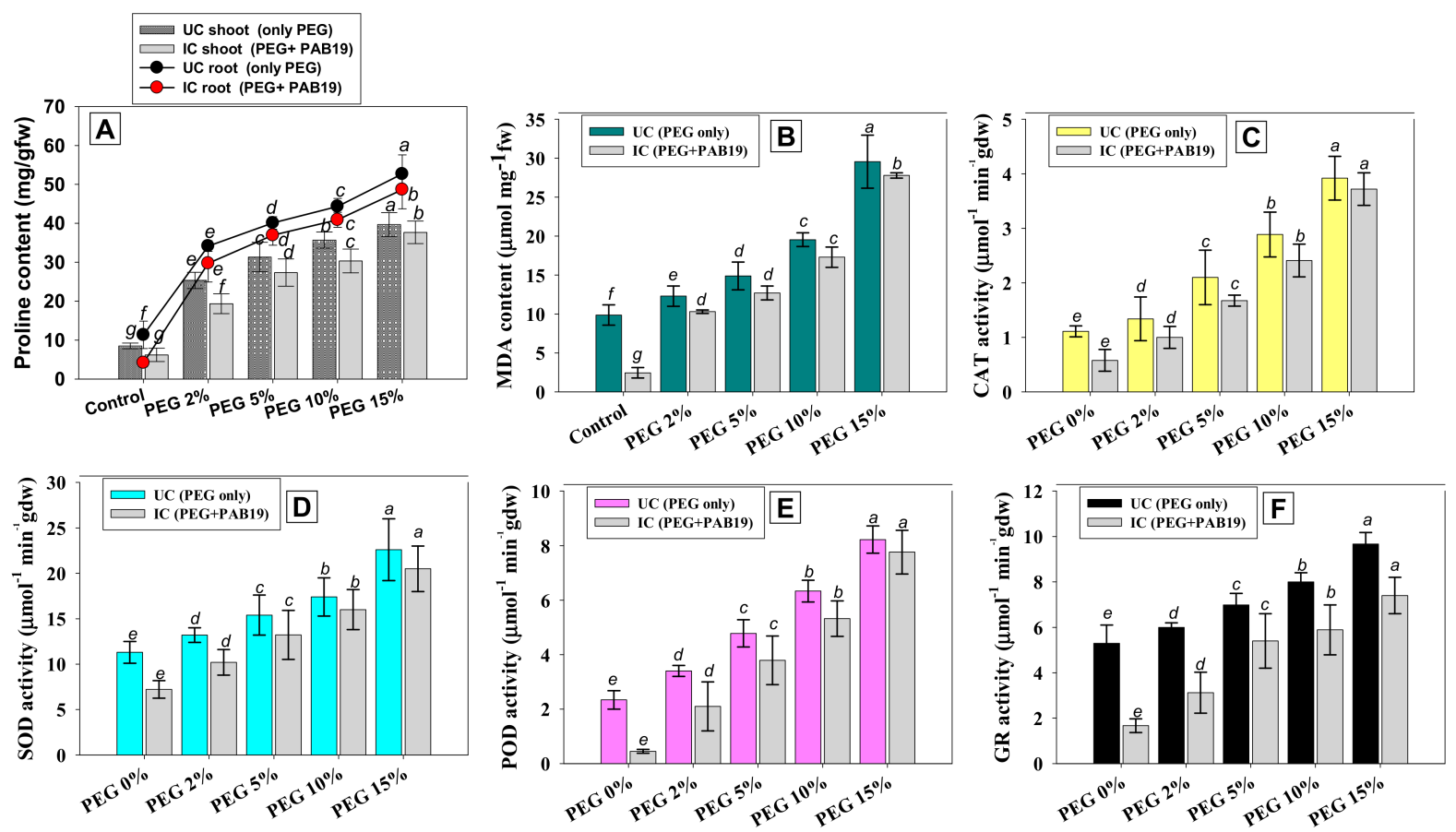

Figure 7. Impact of drought-tolerant Enterobacter sp./L. adecarboxylata PAB19 on stress-related parameters; proline (A) and MDA (B) contents and antioxidant enzyme activities; CAT (C), SOD (D), POD (E), and GR (F) of V. radiata cultivated in the presence of different levels of water stress (2\%, 5\%, 10\% and 15\% PEG-6000) raised under greenhouse conditions. Bar diagrams represent the mean values of three replicates. Mean values followed by different letters are significantly different $(p \leq 0.05)$ as determined by the DMRT. Bar and scatter plots represent means \pm SDs.

\subsubsection{Antioxidative Defense Enzymes}

Plants have antioxidant defense mechanisms to protect themselves from the damaging effects of oxidative stress. We noticed that antioxidant enzyme (AE) activity was increased in the foliage tissues of $V$. radiata on increasing PEG concentrations. PEG had the greatest impact at $15 \%$ on AE activity and increased CAT, SOD, POD, and GR levels by $72 \%, 50 \%$, $84 \%$, and $45 \%$, respectively, over untreated controls (Figure 7, panel C-F). However, PAB19 inoculation mitigated the negative effect of water stress by lowering AE levels in foliage tissues. For example, at a PEG concentration of $\%$, PAB19 significantly reduced CAT, SOD, POD, and GR levels by $25 \%, 22 \%, 38 \%$, and $48 \%$, respectively, versus un-inoculated but $2 \%$ PEG-treated $V$. radiata (Figure 7C-F). Observed reductions in antioxidant enzyme levels in Enterobacter sp./L. adecarboxylata bio-primed plants cultivated in soils containing various levels of PEG may be linked to reduced water deficit, and thus, to less oxidative damage. Here, inoculation of PAB19 reduced the synthesis of these ROS-scavenging enzymes by $V$. radiata plants that showed reduction in oxidative stress. Experiments on bacterialmediated tolerance have evaluated antioxidant enzyme activity to determine the role of the scavenging system under drought stress. This research specifically looked at whether the treatment of drought tolerating PGPR to plants resulted in decreased levels of antioxidant enzymes. In this context, it was discovered that Bacillus subtilis EPB and Pseudomonas fluorescens Pf1 modulated the activity of CAT in V. radiata plants [103]. The changes were shown to be connected to the observed drought tolerance. Additionally, drought-tolerant Ochrobactrum sp. BRISH6 mitigates the toxic effect of deficit water stress and lowered levels of components of the antioxidative defense system, viz., SOD, CAT, APX, POD, GPX, and polyphenol oxidase, in Zea mays [20]. Similarly, PGPR strain P. pseudoalcaligenes alleviated water stress in $Z$. mays and enhanced antioxidant defense enzyme levels by modulating the defense system under different levels of water stress [21]. Likewise, plants treated with drought tolerating strains of Bacillus species acquired drought resistance by lowering the activity of antioxidant enzymes such as APX and GR [71]. 


\subsection{Effect of Enterobacter sp./L. adecarboxylata on the Gas Exchange Parameters of V. radiata under Drought Stress}

Physiological characteristics (stomatal conductance, $\mathrm{CO}_{2}$ concentration, transpiration rate, vapor pressure deficit, intrinsic water use efficiency, and photosynthetic rate) are useful tools for studying the effects of drought stress on a variety of plants. The leaf gas exchange parameters of PEG-treated and strain PAB19 inoculated V. radiata plants were evaluated. Similar trends were observed for gas exchange attributes, that is, stomatal conductance $(g s)$, intercellular $\mathrm{CO}_{2}$ concentration $(\mathrm{Ci})$, rate of transpiration $(E)$, vapor pressure deficit (VpDL), intrinsic water use efficiency (iWUE), and photosynthetic rate $(P \mathrm{~N})$. Under drought conditions, these parameters of $V$. radiata seedlings were significantly $(p \leq 0.05)$ and markedly reduced at 15\% PEG-6000 versus untreated controls. However, seedlings inoculated with PAB19 showed greatest improvement in these parameters. For example, $g \mathrm{~s}, \mathrm{Ci}, E, \mathrm{VpDL}$, iWUE, and $P \mathrm{~N}$ were significantly $(p \leq 0.05)$ increased by $12 \%, 10 \%, 43 \%$, $13 \%, 12 \%$, and $9 \%$ in PAB19 inoculated $V$. radiata plants raised in soil amended with $2 \%$ PEG (Figure 8A-F), which shows PAB19 improves these activities by reducing the impacts of drought stress, which may be due to its high resilience and effective colonization of the rhizosphere. Furthermore, the changes in $\mathrm{CO}_{2}$ assimilation for photosynthesis might result from these improvements in physiological characteristics. Our findings demonstrate that drought tolerating strain PAB19 not only boosts the water and nutrient absorption, but also improves the stomatal conductance, which helps to buffer the detrimental effects of drought. $V$. radiata plants inoculated with strain PAB19 exhibited lower levels of potentials and higher water content in response to drought stress, allowing inoculated and amended plants to maintain high organ hydration and turgor levels, which support overall physiological activities of the cells, particularly those linked to the photosynthetic apparatus. Similarly, inoculation of Platycladus orientalis seedlings with cytokinin-producing Bacillus subtilis enhanced ABA levels in shoots and stomatal conductance, giving drought stress tolerance [104].
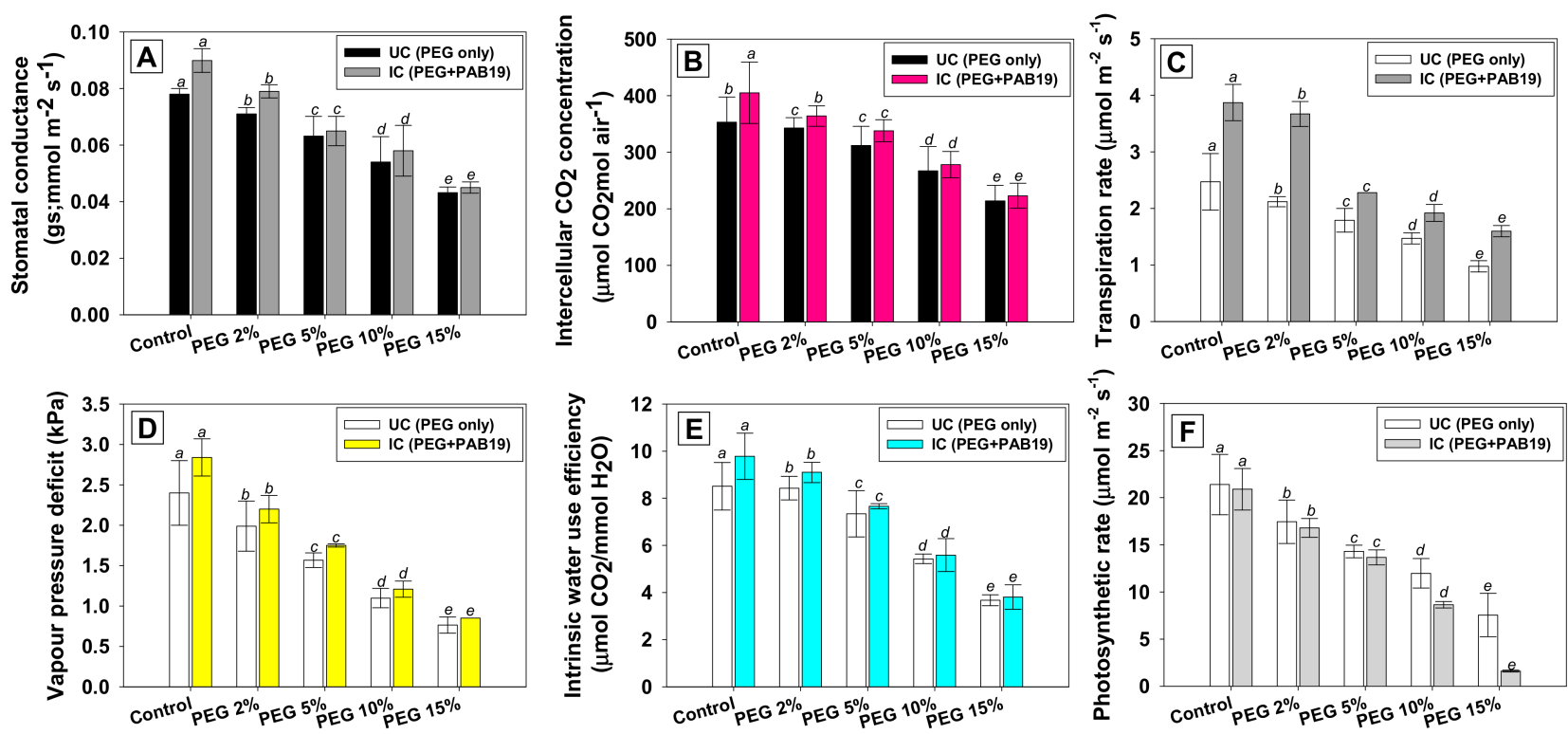

Figure 8. Impact of Enterobacter sp./L. adecarboxylata PAB19 on gas exchange parameters; stomatal conductance (A), intercellular $\mathrm{CO}_{2}$ concentration (B), transpiration rate (C), vapor pressure deficit (D), intrinsic water use efficiency (E), and photosynthetic rate $(\mathbf{F})$ of $V$. radiata cultivated in the presence of different levels of water stress under green-house conditions. Bar and scatter plots represent means \pm SDs. Mean values followed by different letters are significantly different $(p \leq 0.05)$ as determined by the DMRT. 


\subsection{Rhizosphere and Rhizoplane Colonization under Water Deficit Conditions}

Root colonization is an important component of plant/microbe interactions in the rhizosphere. Plant growth and production, and protection from biotic and abiotic factors, may benefit from this symbiotic relationship [105]. PEG untreated but strain PAB19 treated roots exhibited bacterial colonization, whereas the extent of colonization was found less on PEG-treated roots. Bacterial components such as EPS, cell wall polysaccharides, and extracellular bacterial proteins may sustain root surface attachment. At 50 and 80 DAS, rhizosphere and rhizoplane population numbers of strain PAB19 differed. Furthermore, CFU counts of PAB19 were considerably reduced when PEG concentrations were increased. However, PAB19 was able to survive and colonize even at the maximum dose of PEG (15\%); lower PEG doses had comparatively less effect on bacterial population viability counts. Rhizospheric CFU counts of PAB19 were 2.33 and $2.11 \log$ CFU g ${ }^{-1}$ after treatment with $15 \%$ PEG solution and 8.46 and $6.67 \log _{\text {CFU g }}{ }^{-1}$ for untreated controls at 40 and 80 DAS, respectively (Figure S3). Similar trends were observed for rhizoplane counts. As PGPR colonize root surfaces, they proliferate and reproduce by absorbing major signaling chemicals and nutrients from root exudates and form biofilms in the root system. Likewise, drought tolerating PGPR strains viz., Flavobacterium sp., E. ludwigi, and Klebsiella sp., successfully colonized the surface and interior roots of wheat plants even under drought stress as was observed by scanning microscopy [106]. Colonization may have triggered numerous physiological mechanisms that assisted plants in maintaining photosynthesis and plant development under drought stress.

In this study, we have reported the PGP aspect of Enterobacter sp./L. adecarboxylata PAB19 under drought stress. Its pathogenicity cannot be judged in humans since the response of strain PAB19 as an opportunistic pathogen was not studied. However, studies have reported Enterobacter sp./L. adecarboxylata to cause infection in immunocompromised patients. Many of the PGPR strains lack classical pathogenicity genes and the pathogenicity could be a strain specific feature. For example, Burkholderia cepacia and members of the Burkholderia cepacia complex (BCC) have pathogenicity-related genes and given a particular host, have the opportunity to colonize it [107]. Other members of the same genus lack these elements and are the ones that have potential for use as PGPR $[108,109]$. Origin of isolation of a specific strain may also determine its nature as opportunistic human pathogen. For instance, strains of Bacillus subtilis, B. thuringiensis, and Saccharomyces cerevisiae could be opportunistic pathogens $[110,111]$, however, many other strains of these species are widely used as PGPR, biopesticide, in wine and bread industries [112-114]. Further studies are warranted to check the potential pathogenicity of the strain PAB19 before utilizing it as a field inoculant.

\section{Conclusions}

In the scope of sustainable agriculture and environmental health, novel solutions for not only enhancing stress tolerance and crop yields but also lowering farmers' reliance on agrochemicals need to be researched and adopted. We have shown that water deficiency detrimentally affects germination efficiency, biological features, symbiosis, seed characteristics, and nutrient uptake by $V$. radiata. Additionally, leaf exchange parameters were increased and stress biomarkers, antioxidants, and antioxidant enzymes were induced by PEG in $V$. radiata. As an organic strategy for $V$. radiata cultivation, a drought-tolerant PGPR strain of Enterobacter sp./L. adecarboxylata PAB19 capable of withstanding high PEG-6000 concentrations while secreting the plant growth-regulating substances circumvented the drought stress in our experimental conditions. PAB19 inoculation of $V$. radiata protected it from drought stress and enhanced the biological attributes viz., leaf pigments, symbiosis, and yield attributes, and uptake of essential nutrients ( $\mathrm{N}$ and $\mathrm{P}$ ) were simultaneously enhanced. The improvement due to PAB19 inoculation-induced mitigation of stress was a result of the release of active PGP substances following rhizosphere and rhizoplane colonization by PAB19. Additionally, our findings suggest that strain PAB19 develops drought-adaptive strategies and affects some of the essential plant processes such as photo- 
synthesis, antioxidant enzyme production, leaf-exchange characteristics, and decreased lipid peroxidation. To summarize, the drought-tolerant PGPR strain Enterobacter sp./L. adecarboxylata PAB19 offers an appealing, agronomically viable, and long-term potential alternative for $V$. radiata cultivation even under drought conditions.

Supplementary Materials: The following are available online at https:/ /www.mdpi.com/article/10 .3390 /biology10111149/s1, Figure S1. Representative pictures of bio-inoculated V. radiata plants with drought-tolerating Enterobacter sp./L. adecarboxylata PAB19 growing with 2\%, 5\%, 10\%, and $15 \%$ PEG solution in the soil., Figure S2. Impacts of PAB19 on yield parameters; pod number (A), pod yield (B), seed number (C), seed yield (D), and protein content (E) of V. radiata cultivated in the presence of different levels of water stress $(2 \%, 5 \%, 10 \%$ and $15 \%$ PEG-6000) under green-house conditions. Bar diagrams represent the mean values of three replicates. Mean values fol-lowed by different letters are significantly different $(p \leq 0.05)$ as determined by the DMRT test, Figure S3. Colonization of the root surfaces of V. radiata by Enterobacter sp./L. adecarboxylata strain PAB19. Rhizoplane and rhizosphere colonization in the presence of different levels of PEG at two different seeding stages (50 and 80 DAS). Mean values followed by different letters are significantly different $(p \leq 0.05)$ as determined by the DMRT.

Author Contributions: Conceptualization, B.A. and M.S.; methodology, A.S., M.S., B.A. and V.D.R.; software, M.S., B.A. and A.S.; validation, A.M.E., J.L., T.M. and A.H.B.; formal analysis, J.L., A.M.E., A.S., V.D.R. and A.H.B.; investigation, M.S., B.A. and A.S.; resources, J.L., A.S., A.M.E. and A.H.B.; data curation, M.S., B.A., A.S. and V.D.R.; writing-original draft preparation, B.A. and M.S.; writingreview and editing, B.A., M.S., J.L., A.S., V.D.R., A.M.E., T.M. and A.H.B.; supervision, J.L., A.S., A.M.E.; project administration, J.L., A.S. and B.A.; funding acquisition, J.L. and A.S. All authors have read and agreed to the published version of the manuscript.

Funding: This research was funded by the Priority Research Center Program through the National Research Foundation of Korea (NRF) funded by the Ministry of Education (grant no. 2014R1A6A1031189) and the Researchers Supporting Project Number (RSP-2021/15) King Saud University, Riyadh, Saudi Arabia.

Institutional Review Board Statement: Not applicable.

Informed Consent Statement: Not applicable.

Data Availability Statement: The data presented in this study are available in the main manuscript and in the supplementary material here.

Acknowledgments: This work was supported by the Priority Research Center Program through the National Research Foundation of Korea (NRF) funded by the Ministry of Education (grant no. 2014R1A6A1031189). The authors extend their appreciation to The Researchers Supporting Project Number (RSP-2021/15) King Saud University, Riyadh, Saudi Arabia. Authors would also like to recognize the financial support from the Ministry of Science and Higher Education of the Russian Federation within the framework of the state task in the field of scientific activity (no. 0852-2020-0029).

Conflicts of Interest: The authors declare no conflict of interest.

\section{References}

1. Rizvi, A.; Ahmed, B.; Zaidi, A.; Khan, M.S.M.S. Heavy metal mediated phytotoxic impact on winter wheat: Oxidative stress and microbial management of toxicity by: Bacillus subtilis BM2. RSC Adv. 2019, 9, 6125-6142. [CrossRef]

2. Shahid, M.; Ahmed, B.; Khan, M.S. Evaluation of microbiological management strategy of herbicide toxicity to greengram plants. Biocatal. Agric. Biotechnol. 2018, 14, 96-108. [CrossRef]

3. Lin, X.; Shu, D.; Zhang, J.; Chen, J.; Zhou, Y.; Chen, C. Dynamics of particle retention and physiology in Euonymus japonicus Thunb. var. aurea-marginatus Hort. with severe exhaust exposure under continuous drought. Environ. Pollut. 2021, $285,117194$. [CrossRef] [PubMed]

4. Bartholomeus, R.P.; Witte, J.M.; van Bodegom, P.M.; van Dam, J.C.; Aerts, R. Climate change threatens endangered plant species by stronger and interacting water-related stresses. J. Geophys. Res. Biogeosci. 2011, 116, G04023. [CrossRef]

5. Liu, C.; Dai, Z.; Cui, M.; Lu, W.; Sun, H. Arbuscular mycorrhizal fungi alleviate boron toxicity in Puccinellia tenuiflora under the combined stresses of salt and drought. Environ. Pollut. 2018, 240, 557-565. [CrossRef]

6. Le Page, M.; Fakir, Y.; Jarlan, L.; Boone, A.; Berjamy, B.; Khabba, S.; Zribi, M. Projection of irrigation water demand based on the simulation of synthetic crop coefficients and climate change. Hydrol. Earth Syst. Sci. 2021, 25, 637-651. [CrossRef] 
7. Anjum, S.A.; Xie, X.Y.; Wang, L.C.; Saleem, M.F.; Man, C.; Lei, W. Morphological, physiological and biochemical responses of plants to drought stress. Afr. J. Agric. Res. 2011, 6, 2026-2032.

8. Holmstrup, M.; Slotsbo, S.; Schmidt, S.N.; Mayer, P.; Damgaard, C.; Sørensen, J.G. Physiological and molecular responses of springtails exposed to phenanthrene and drought. Environ. Pollut. 2014, 184, 370-376. [CrossRef]

9. Nautiyal, C.S.; Srivastava, S.; Chauhan, P.S.; Seem, K.; Mishra, A.; Sopory, S.K. Plant growth-promoting bacteria Bacillus amyloliquefaciens NBRISN13 modulates gene expression profile of leaf and rhizosphere community in rice during salt stress. Plant Physiol. Biochem. 2013, 66, 1-9. [CrossRef]

10. Tang, D.; Dong, Y.; Ren, H.; Li, L.; He, C. A review of phytochemistry, metabolite changes, and medicinal uses of the common food mung bean and its sprouts (Vigna radiata). Chem. Cent. J. 2014, 8, 1-9. [CrossRef]

11. Zaidi, A.; Khan, M.S.; Rizvi, A.; Saif, S.; Ahmad, B.; Shahid, M. Role of phosphate-solubilizing bacteria in legume improvement. In Microbes for Legume Improvement; Springer: Cham, Switzerland, 2017; pp. 175-197.

12. Zaidi, A.; Khan, M.S.; Saif, S.; Rizvi, A.; Ahmed, B.; Shahid, M. Role of Nitrogen-Fixing Plant Growth-Promoting Rhizobacteria in Sustainable Production of Vegetables: Current Perspective. In Microbial Strategies for Vegetable Production; Springer: Cham, Switzerland, 2017; ISBN 9783319544014

13. Kim, Y.-J.; Lim, J.; Sukweenadhi, J.; Seok, J.W.; Lee, S.-W.; Park, J.C.; Taizhanova, A.; Kim, D.; Yang, D.C. Genomic characterization of a newly isolated rhizobacteria Sphingomonas panacis reveals plant growth promoting effect to rice. Biotechnol. Bioprocess Eng. 2019, 24, 119-125. [CrossRef]

14. Ahmed, B.; Zaidi, A.; Khan, M.S.; Rizvi, A.; Saif, S.; Shahid, M. Perspectives of Plant Growth Promoting Rhizobacteria in Growth Enhancement and Sustainable Production of Tomato. In Microbial Strategies for Vegetable Production; Springer: Cham, Switzerland, 2017; ISBN 9783319544014.

15. Rizvi, A.; Zaidi, A.; Ameen, F.; Ahmed, B.; AlKahtani, M.D.F.; Khan, M.S. Heavy metal induced stress on wheat: Phytotoxicity and microbiological management. RSC Adv. 2020, 10, 38379-38403. [CrossRef]

16. Rizvi, A.; Ahmed, B.; Zaidi, A.; Khan, M.S.M.S. Bioreduction of toxicity influenced by bioactive molecules secreted under metal stress by Azotobacter chroococcum. Ecotoxicology 2019, 28, 302-322. [CrossRef] [PubMed]

17. Wang, Y.; Selvamani, V.; Yoo, I.-K.; Kim, T.W.; Hong, S.H. A Novel Strategy for the Microbial Removal of Heavy Metals: Cell-surface Display of Peptides. Biotechnol. Bioprocess Eng. 2021, 26, 1-9. [CrossRef]

18. Timmusk, S.; Abd El-Daim, I.A.; Copolovici, L.; Tanilas, T.; Kännaste, A.; Behers, L.; Nevo, E.; Seisenbaeva, G.; Stenström, E.; Niinemets, Ü. Drought-tolerance of wheat improved by rhizosphere bacteria from harsh environments: Enhanced biomass production and reduced emissions of stress volatiles. PLoS ONE 2014, 9, e96086. [CrossRef] [PubMed]

19. Ahmed, B.; Ameen, F.; Rizvi, A.; Ali, K.; Sonbol, H.; Zaidi, A.; Khan, M.S.; Musarrat, J. Destruction of Cell Topography, Morphology, Membrane, Inhibition of Respiration, Biofilm Formation, and Bioactive Molecule Production by Nanoparticles of $\mathrm{Ag}, \mathrm{ZnO}, \mathrm{CuO}, \mathrm{TiO}_{2}$, and $\mathrm{Al}_{2} \mathrm{O}_{3}$ toward Beneficial Soil Bacteria. ACS Omega 2020, 5, 7861-7876. [CrossRef]

20. Mishra, S.K.; Khan, M.H.; Misra, S.; Dixit, V.K.; Gupta, S.; Tiwari, S.; Gupta, S.C.; Chauhan, P.S. Drought tolerant Ochrobactrum sp inoculation performs multiple roles in maintaining the homeostasis in Zea mays L. subjected to deficit water stress. Plant Physiol. Biochem. 2020, 150, 1-14. [CrossRef]

21. Yasmin, H.; Rashid, U.; Hassan, M.N.; Nosheen, A.; Naz, R.; Ilyas, N.; Sajjad, M.; Azmat, A.; Alyemeni, M.N. Volatile organic compounds produced by Pseudomonas pseudoalcaligenes alleviated drought stress by modulating defense system in maize (Zea mays L.). Physiol. Plant. 2021, 172, 896-911. [CrossRef]

22. Danish, S.; Zafar-Ul-Hye, M.; Hussain, S.; Riaz, M.; Qayyum, M.F. Mitigation of drought stress in maize through inoculation with drought tolerant ACC deaminase containing PGPR under axenic conditions. Pak. J. Bot. 2020, 52, 49-60. [CrossRef]

23. Kang, S.-M.; Adhikari, A.; Lee, K.-E.; Khan, M.A.; Shahzad, R.; Dhungana, S.K.; Lee, I.-J. Inoculation with Indole-3-acetic acid-producing rhizospheric Rhodobacter sphaeroides KE149 augments growth of adzuki bean plants under water stress. J. Microbiol. Biotechnol. 2020, 30, 717-725. [CrossRef]

24. Ke, T.; Guo, G.; Liu, J.; Zhang, C.; Tao, Y.; Wang, P.; Xu, Y.; Chen, L. Improvement of the Cu and Cd phytostabilization efficiency of perennial ryegrass through the inoculation of three metal-resistant PGPR strains. Environ. Pollut. 2021, 271, 116314. [CrossRef]

25. Shahid, M.; Khan, M.S.; Ahmed, B.; Syed, A.; Bahkali, A.H. Physiological disruption, structural deformation and low grain yield induced by neonicotinoid insecticides in chickpea: A long term phytotoxicity investigation. Chemosphere 2020, 262, 128388. [CrossRef] [PubMed]

26. Syed, A.; Zeyad, M.T.; Shahid, M.; Elgorban, A.M.; Alkhulaifi, M.M.; Ansari, I.A. Heavy Metals Induced Modulations in Growth, Physiology, Cellular Viability, and Biofilm Formation of an Identified Bacterial Isolate. ACS Omega 2021, 6, 25076-25088. [CrossRef] [PubMed]

27. Bric, J.M.; Bostock, R.M.; Silverstone, S.E. Rapid in situ assay for indoleacetic acid production by bacteria immobilized on a nitrocellulose membrane. Appl. Environ. Microbiol. 1991, 57, 535-538. [CrossRef]

28. Barbhaiya, H.B.; Rao, K.K. Production of pyoverdine, the fluorescent pigment of Pseudomonas aeruginosa PAO1. FEMS Microbiol. Lett. 1985, 27, 233-235. [CrossRef]

29. Schwyn, B.; Neilands, J.B. Universal chemical assay for the detection and determination of siderophores. Anal. Biochem. 1987, 160, 47-56. [CrossRef]

30. Honma, M.; Shimomura, T. Metabolism of 1-aminocyclopropane-1-carboxylic acid. Agric. Biol. Chem. 1978, 42, $1825-1831$. 
31. Penrose, D.M.; Glick, B.R. Methods for isolating and characterizing ACC deaminase-containing plant growth-promoting rhizobacteria. Physiol. Plant. 2003, 118, 10-15. [CrossRef]

32. Jackson, M.L. Soil Chemical Analysis: Advanced Course; UW-Madison Libraries Parallel Press: Madison, WI, USA, 2005; ISBN 1893311473.

33. Bakker, A.W.; Schippers, B.O.B. Microbial cyanide production in the rhizosphere in relation to potato yield reduction and Pseudomonas spp-mediated plant growth-stimulation. Soil Biol. Biochem. 1987, 19, 451-457. [CrossRef]

34. Dye, D.W. The inadequacy of the usual determinative tests for the identification of Xanthomonas spp. N. Z. J. Sci. 1962, 5, 393-416.

35. O’Toole, G.A. Microtiter dish biofilm formation assay. J. Vis. Exp. JoVE 2011, 47, e2437. [CrossRef] [PubMed]

36. Mody, B.; Bindra, M.; Modi, V. Extracellular polysaccharides of cowpea rhizobia: Compositional and functional studies. Arch. Microbiol. 1989, 153, 38-42. [CrossRef]

37. Rosenberg, M. Bacterial adherence to hydrocarbons: A useful technique for studying cell surface hydrophobicity. FEMS Microbiol. Lett. 1984, 22, 289-295. [CrossRef]

38. Arnon, D.I. Copper Enzymes in Isolated Chloroplasts. Polyphenoloxidase in Beta Vulgaris. Plant Physiol. 1949, $24,1-15$. [CrossRef] [PubMed]

39. Kirk, J.T.O.; Allen, R.L. Dependence of chloroplast pigment synthesis on protein synthesis: Effect of actidione. Biochem. Biophys. Res. Commun. 1965, 21, 523-530. [CrossRef]

40. Jackson, W.A.; Kwik, K.D.; Volk, R.J. Nitrate uptake during recovery from nitrogen deficiency. Physiol. Plant. 1976, 36, $174-181$. [CrossRef]

41. Lindner, R.C. Rapid analytical methods for some of the more common inorganic constituents of plant tissues. Plant Physiol. 1944, 19, 76. [CrossRef]

42. Lowry, O.H.; Rosebrough, N.J.; Farr, A.L.; Randall, R.J. Protein measurement with the Folin phenol reagent. J. Biol. Chem. 1951, 193, 265-275. [CrossRef]

43. Shahid, M.; Ameen, F.; Maheshwari, H.S.; Ahmed, B.; AlNadhari, S.; Khan, M.S. Colonization of Vigna radiata by a halotolerant bacterium Kosakonia sacchari improves the ionic balance, stressor metabolites, antioxidant status and yield under $\mathrm{NaCl}$ stress. Appl. Soil Ecol. 2021, 158, 103809. [CrossRef]

44. Khan, S.; Shahid, M.; Khan, M.S.; Syed, A.; Bahkali, A.H.; Elgorban, A.M.; Pichtel, J. Fungicide-tolerant plant growth-promoting rhizobacteria mitigate physiological disruption of white radish caused by fungicides used in the field cultivation. Int. J. Environ. Res. Public Health 2020, 17, 7251. [CrossRef]

45. Beers, R.F.; Sizer, I.W. A spectrophotometric method for measuring the breakdown of hydrogen peroxide by catalase. J. Biol. Chem. 1952, 195, 133-140. [CrossRef]

46. Beauchamp, C.; Fridovich, I. Superoxide dismutase: Improved assays and an assay applicable to acrylamide gels. Anal. Biochem. 1971, 44, 276-287. [CrossRef]

47. Jablonski, P.P.; Anderson, J.W. Light-dependent reduction of oxidized glutathione by ruptured chloroplasts. Plant Physiol. 1978, 61, 221-225. [CrossRef] [PubMed]

48. Danish, S.; Zafar-ul-Hye, M.; Mohsin, F.; Hussain, M. ACC-deaminase producing plant growth promoting rhizobacteria and biochar mitigate adverse effects of drought stress on maize growth. PLoS ONE 2020, 15, e0230615. [CrossRef]

49. Shahzad, R.; Waqas, M.; Khan, A.L.; Al-Hosni, K.; Kang, S.-M.; Seo, C.-W.; Lee, I.-J. Indoleacetic acid production and plant growth promoting potential of bacterial endophytes isolated from rice (Oryza sativa L.) seeds. Acta Biol. Hung. 2017, 68, 175-186. [CrossRef] [PubMed]

50. Patten, C.L.; Glick, B.R. Bacterial biosynthesis of indole-3-acetic acid. Can. J. Microbiol. 1996, 42, 207-220. [CrossRef] [PubMed]

51. Deinum, E.E.; Kohlen, W.; Geurts, R. Quantitative modelling of legume root nodule primordium induction by a diffusive signal of epidermal origin that inhibits auxin efflux. BMC Plant Biol. 2016, 16, 1-14. [CrossRef]

52. Mehmood, A.; Khan, N.; Irshad, M.; Hamayun, M.; Husna, I.; Javed, A.; Hussain, A. IAA producing endopytic fungus Fusariun oxysporum wlw colonize maize roots and promoted maize growth under hydroponic condition. Eur. Exp. Biol. 2018, 8, 24. [CrossRef]

53. Glick, B.R. Plant growth-promoting bacteria: Mechanisms and applications. Scientifica 2012, 2012, 1-15. [CrossRef]

54. Kang, S.-M.; Radhakrishnan, R.; Khan, A.L.; Kim, M.-J.; Park, J.-M.; Kim, B.-R.; Shin, D.-H.; Lee, I.-J. Gibberellin secreting rhizobacterium, Pseudomonas putida H-2-3 modulates the hormonal and stress physiology of soybean to improve the plant growth under saline and drought conditions. Plant Physiol. Biochem. 2014, 84, 115-124. [CrossRef]

55. Trapet, P.; Avoscan, L.; Klinguer, A.; Pateyron, S.; Citerne, S.; Chervin, C.; Mazurier, S.; Lemanceau, P.; Wendehenne, D.; BessonBard, A. The Pseudomonas fluorescens siderophore pyoverdine weakens Arabidopsis thaliana defense in favor of growth in iron-deficient conditions. Plant Physiol. 2016, 171, 675-693. [CrossRef] [PubMed]

56. Mishra, A.K.; Baek, K.-H. Salicylic Acid Biosynthesis and Metabolism: A Divergent Pathway for Plants and Bacteria. Biomolecules 2021, 11, 705. [CrossRef] [PubMed]

57. Chipperfield, J.R.; Ratledge, C. Salicylic acid is not a bacterial siderophore: A theoretical study. Biometals 2000, 13, 165-168. [CrossRef] [PubMed]

58. Yu, X.; Ai, C.; Xin, L.; Zhou, G. The siderophore-producing bacterium, Bacillus subtilis CAS15, has a biocontrol effect on Fusarium wilt and promotes the growth of pepper. Eur. J. Soil Biol. 2011, 47, 138-145. [CrossRef] 
59. Singh, S.; Gupta, R.; Kumari, M.; Sharma, S. Nontarget effects of chemical pesticides and biological pesticide on rhizospheric microbial community structure and function in Vigna radiata. Environ. Sci. Pollut. Res. 2015, 22, 11290-11300. [CrossRef]

60. Macleod, K.; Rumbold, K.; Padayachee, K. A systems approach to uncover the effects of the PGPR Pseudomonas koreensis on the level of drought stress tolerance in Helianthus annuus. Procedia Environ. Sci. 2015, 29, 262-263. [CrossRef]

61. Arzanesh, M.H.; Alikhani, H.A.; Khavazi, K.; Rahimian, H.A.; Miransari, M. Wheat (Triticum aestivum L.) growth enhancement by Azospirillum sp. under drought stress. World J. Microbiol. Biotechnol. 2011, 27, 197-205. [CrossRef]

62. Ansari, F.A.; Jabeen, M.; Ahmad, I. Pseudomonas azotoformans FAP5, a novel biofilm-forming PGPR strain, alleviates drought stress in wheat plant. Int. J. Environ. Sci. Technol. 2021, 18, 1-16. [CrossRef]

63. Augusto, L.; Achat, D.L.; Jonard, M.; Vidal, D.; Ringeval, B. Soil parent material—A major driver of plant nutrient limitations in terrestrial ecosystems. Glob. Chang. Biol. 2017, 23, 3808-3824. [CrossRef]

64. Soumare, A.; Boubekri, K.; Lyamlouli, K.; Hafidi, M.; Ouhdouch, Y.; Kouisni, L. From isolation of phosphate solubilizing microbes to their formulation and use as biofertilizers: Status and needs. Front. Bioeng. Biotechnol. 2020, 7, 425. [CrossRef]

65. Kour, D.; Rana, K.L.; Sheikh, I.; Kumar, V.; Yadav, A.N.; Dhaliwal, H.S.; Saxena, A.K. Alleviation of drought stress and plant growth promotion by Pseudomonas libanensis EU-LWNA-33, a drought-adaptive phosphorus-solubilizing bacterium. Proc. Natl. Acad. Sci. India Sect. B Biol. Sci. 2019, 90, 785-795. [CrossRef]

66. García, J.E.; Maroniche, G.; Creus, C.; Suárez-Rodríguez, R.; Ramirez-Trujillo, J.A.; Groppa, M.D. In vitro PGPR properties and osmotic tolerance of different Azospirillum native strains and their effects on growth of maize under drought stress. Microbiol. Res. 2017, 202, 21-29. [CrossRef] [PubMed]

67. Naseem, H.; Bano, A. Role of plant growth-promoting rhizobacteria and their exopolysaccharide in drought tolerance of maize. J. Plant Interact. 2014, 9, 689-701. [CrossRef]

68. Kumar, M.; Mishra, S.; Dixit, V.; Kumar, M.; Agarwal, L.; Chauhan, P.S.; Nautiyal, C.S. Synergistic effect of Pseudomonas putida and Bacillus amyloliquefaciens ameliorates drought stress in chickpea (Cicer arietinum L.). Plant Signal. Behav. 2016, 11, e1071004. [CrossRef] [PubMed]

69. Danish, S.; Zafar-ul-Hye, M. Co-application of ACC-deaminase producing PGPR and timber-waste biochar improves pigments formation, growth and yield of wheat under drought stress. Sci. Rep. 2019, 9, 1-13. [CrossRef]

70. Barnawal, D.; Bharti, N.; Pandey, S.S.; Pandey, A.; Chanotiya, C.S.; Kalra, A. Plant growth-promoting rhizobacteria enhance wheat salt and drought stress tolerance by altering endogenous phytohormone levels and TaCTR1/TaDREB2 expression. Physiol. Plant. 2017, 161, 502-514. [CrossRef] [PubMed]

71. Vardharajula, S.; Zulfikar Ali, S.; Grover, M.; Reddy, G.; Bandi, V. Drought-tolerant plant growth promoting Bacillus spp.: Effect on growth, osmolytes, and antioxidant status of maize under drought stress. J. Plant Interact. 2011, 6, 1-14. [CrossRef]

72. Kour, D.; Rana, K.L.; Yadav, A.N.; Sheikh, I.; Kumar, V.; Dhaliwal, H.S.; Saxena, A.K. Amelioration of drought stress in Foxtail millet (Setaria italica L.) by P-solubilizing drought-tolerant microbes with multifarious plant growth promoting attributes. Environ. Sustain. 2020, 3, 23-34. [CrossRef]

73. Kasim, W.A.; Gaafar, R.M.; Abou-Ali, R.M.; Omar, M.N.; Hewait, H.M. Effect of biofilm forming plant growth promoting rhizobacteria on salinity tolerance in barley. Ann. Agric. Sci. 2016, 61, 217-227. [CrossRef]

74. Ahmed, B.; Syed, A.; Rizvi, A.; Shahid, M.; Bahkali, A.H.; Khan, M.S.; Musarrat, J. Impact of metal-oxide nanoparticles on growth, physiology and yield of tomato (Solanum lycopersicum L.) modulated by Azotobacter salinestris strain ASM. Environ. Pollut. 2021, 269, 116218. [CrossRef] [PubMed]

75. Sá, C.; Cardoso, P.; Figueira, E. Alginate as a feature of osmotolerance differentiation among soil bacteria isolated from wild legumes growing in Portugal. Sci. Total Environ. 2019, 681, 312-319. [CrossRef] [PubMed]

76. Egamberdieva, D.; Wirth, S.; Bellingrath-Kimura, S.D.; Mishra, J.; Arora, N.K. Salt-tolerant plant growth promoting rhizobacteria for enhancing crop productivity of saline soils. Front. Microbiol. 2019, 10, 2791. [CrossRef] [PubMed]

77. Chua, S.L.; Liu, Y.; Yam, J.K.H.; Chen, Y.; Vejborg, R.M.; Tan, B.G.C.; Kjelleberg, S.; Tolker-Nielsen, T.; Givskov, M.; Yang, L. Dispersed cells represent a distinct stage in the transition from bacterial biofilm to planktonic lifestyles. Nat. Commun. 2014, 5, 1-12. [CrossRef] [PubMed]

78. Bester, E.; Wolfaardt, G.; Joubert, L.; Garny, K.; Saftic, S. Planktonic-cell yield of a pseudomonad biofilm. Appl. Environ. Microbiol. 2005, 71, 7792-7798. [CrossRef] [PubMed]

79. Ghosh, D.; Gupta, A.; Mohapatra, S. A comparative analysis of exopolysaccharide and phytohormone secretions by four droughttolerant rhizobacterial strains and their impact on osmotic-stress mitigation in Arabidopsis thaliana. World J. Microbiol. Biotechnol. 2019, 35, 1-15. [CrossRef]

80. Rosenberg, M.; Gutnick, D.; Rosenberg, E. Adherence of bacteria to hydrocarbons: A simple method for measuring cell-surface hydrophobicity. FEMS Microbiol. Lett. 1980, 9, 29-33. [CrossRef]

81. Sabeti, M.; Tahmasebi, P.; Ghehsareh Ardestani, E.; Nikookhah, F. Effect of plant growth promoting Rhizobacteria (PGPR) on the seed germination, seedling growth and photosynthetic pigments of Astragalus caragana under drought stress. J. Rangel. Sci. 2019, 9, 364-377.

82. Sharma, P.; Khanna, V.; Kumari, P. Efficacy of aminocyclopropane-1-carboxylic acid (ACC)-deaminase-producing rhizobacteria in ameliorating water stress in chickpea under axenic conditions. Afr. J. Microbiol. Res. 2013, 7, 5749-5757.

83. Baroowa, B.; Gogoi, N.; Farooq, M. Changes in physiological, biochemical and antioxidant enzyme activities of green gram (Vigna radiata L.) genotypes under drought. Acta Physiol. Plant. 2016, 38, 1-10. [CrossRef] 
84. Asghari, B.; Khademian, R.; Sedaghati, B. Plant growth promoting rhizobacteria (PGPR) confer drought resistance and stimulate biosynthesis of secondary metabolites in pennyroyal (Mentha pulegium L.) under water shortage condition. Sci. Hortic. 2020, 263, 109132. [CrossRef]

85. Zhang, M.; Yang, L.; Hao, R.; Bai, X.; Wang, Y.; Yu, X. Drought-tolerant plant growth-promoting rhizobacteria isolated from jujube (Ziziphus jujuba) and their potential to enhance drought tolerance. Plant Soil 2020, 452, 423-440. [CrossRef]

86. Lim, J.-H.; Kim, S.-D. Induction of drought stress resistance by multi-functional PGPR Bacillus licheniformis K11 in pepper. Plant Pathol. J. 2013, 29, 201. [CrossRef]

87. Yasmin, H.; Nosheen, A.; Naz, R.; Bano, A.; Keyani, R. L-tryptophan-assisted PGPR-mediated induction of drought tolerance in maize (Zea mays L.). J. Plant Interact. 2017, 12, 567-578. [CrossRef]

88. Yang, X.; Tang, Z.; Ji, C.; Liu, H.; Ma, W.; Mohhamot, A.; Shi, Z.; Sun, W.; Wang, T.; Wang, X.; et al. Scaling of nitrogen and phosphorus across plant organs in shrubland biomes across Northern China. Sci. Rep. 2014, 4, 1-7. [CrossRef] [PubMed]

89. Pereira, S.I.A.; Abreu, D.; Moreira, H.; Vega, A.; Castro, P.M.L. Plant growth-promoting rhizobacteria (PGPR) improve the growth and nutrient use efficiency in maize (Zea mays L.) under water deficit conditions. Heliyon 2020, 6, e05106. [CrossRef] [PubMed]

90. Adesemoye, A.O.; Torbert, H.A.; Kloepper, J.W. Enhanced plant nutrient use efficiency with PGPR and AMF in an integrated nutrient management system. Can. J. Microbiol. 2008, 54, 876-886. [CrossRef] [PubMed]

91. Khalilpour, M.; Mozafari, V.; Abbaszadeh-Dahaji, P. Tolerance to salinity and drought stresses in pistachio (Pistacia vera L.) seedlings inoculated with indigenous stress-tolerant PGPR isolates. Sci. Hortic. 2021, 289, 110440. [CrossRef]

92. Mondal, H.K.; Mehta, S.; Kaur, H.; Gera, R. Characterization of stress tolerant mungbean rhizobia as PGPR and plant growth promotion under abiotic stress. Indian Ecol. Soc. 2017, 44, 38.

93. Dodd, I.C.; Belimov, A.A.; Sobeih, W.Y.; Safronova, V.I.; Grierson, D.; Davies, W.J. Will modifying plant ethylene status improve plant productivity in water-limited environments. In Proceedings of the 4th International Crop Science Congress, Brisbane, Australia, 26 September-1 October 2004; Volume 26.

94. Figueiredo, M.V.B.; Burity, H.A.; Martinez, C.R.; Chanway, C.P. Alleviation of drought stress in the common bean (Phaseolus vulgaris L.) by co-inoculation with Paenibacillus polymyxa and Rhizobium tropici. Appl. Soil Ecol. 2008, 40, 182-188. [CrossRef]

95. Arshad, M.; Shaharoona, B.; Mahmood, T. Inoculation with Pseudomonas spp. containing ACC-deaminase partially eliminates the effects of drought stress on growth, yield, and ripening of pea (Pisum sativum L.). Pedosphere 2008, 18, 611-620. [CrossRef]

96. Belimov, A.A.; Dodd, I.C.; Hontzeas, N.; Theobald, J.C.; Safronova, V.I.; Davies, W.J. Rhizosphere bacteria containing 1aminocyclopropane-1-carboxylate deaminase increase yield of plants grown in drying soil via both local and systemic hormone signalling. New Phytol. 2009, 181, 413-423. [CrossRef]

97. Raheem, A.; Shaposhnikov, A.; Belimov, A.A.; Dodd, I.C.; Ali, B. Auxin production by rhizobacteria was associated with improved yield of wheat (Triticum aestivum L.) under drought stress. Arch. Agron. Soil Sci. 2018, 64, 574-587. [CrossRef]

98. Furlan, A.L.; Bianucci, E.; Giordano, W.; Castro, S.; Becker, D.F. Proline metabolic dynamics and implications in drought tolerance of peanut plants. Plant Physiol. Biochem. 2020, 151, 566-578. [CrossRef]

99. Siddique, A.; Kandpal, G.; Kumar, P. Proline accumulation and its defensive role under diverse stress condition in plants: An Overview. J. Pure Appl. Microbiol. 2018, 12, 1655-1659. [CrossRef]

100. Khan, N.; Zandi, P.; Ali, S.; Mehmood, A.; Adnan Shahid, M.; Yang, J. Impact of salicylic acid and PGPR on the drought tolerance and phytoremediation potential of Helianthus annus. Front. Microbiol. 2018, 9, 2507. [CrossRef] [PubMed]

101. Khan, N.; Bano, A.; Zandi, P. Effects of exogenously applied plant growth regulators in combination with PGPR on the physiology and root growth of chickpea (Cicer arietinum) and their role in drought tolerance. J. Plant Interact. 2018, 13, 239-247. [CrossRef]

102. Gusain, Y.S.; Singh, U.S.; Sharma, A.K. Bacterial mediated amelioration of drought stress in drought tolerant and susceptible cultivars of rice (Oryza sativa L.). Afr. J. Biotechnol. 2015, 14, 764-773.

103. Saravanakumar, D.; Kavino, M.; Raguchander, T.; Subbian, P.; Samiyappan, R. Plant growth promoting bacteria enhance water stress resistance in green gram plants. Acta Physiol. Plant. 2011, 33, 203-209. [CrossRef]

104. Liu, F.; Xing, S.; Ma, H.; Du, Z.; Ma, B. Cytokinin-producing, plant growth-promoting rhizobacteria that confer resistance to drought stress in Platycladus orientalis container seedlings. Appl. Microbiol. Biotechnol. 2013, 97, 9155-9164. [CrossRef] [PubMed]

105. Kumar, A.; Verma, J.P. Does plant-microbe interaction confer stress tolerance in plants: A review? Microbiol. Res. 2018, 207, 41-52. [CrossRef]

106. Gontia-Mishra, I.; Sapre, S.; Sharma, A.; Tiwari, S. Amelioration of drought tolerance in wheat by the interaction of plant growth-promoting rhizobacteria. Plant Biol. 2016, 18, 992-1000. [CrossRef]

107. Nunvar, J.; Kalferstova, L.; Bloodworth, R.A.M.; Kolar, M.; Degrossi, J.; Lubovich, S.; Cardona, S.T.; Drevinek, P. Understanding the pathogenicity of Burkholderia contaminans, an emerging pathogen in cystic fibrosis. PLoS ONE 2016, 11, e0160975. [CrossRef]

108. You, M.; Fang, S.; MacDonald, J.; Xu, J.; Yuan, Z.-C. Isolation and characterization of Burkholderia cenocepacia CR318, a phosphate solubilizing bacterium promoting corn growth. Microbiol. Res. 2020, 233, 126395. [CrossRef] [PubMed]

109. Vial, L.; Chapalain, A.; Groleau, M.; Déziel, E. The various lifestyles of the Burkholderia cepacia complex species: A tribute to adaptation. Environ. Microbiol. 2011, 13, 1-12. [CrossRef] [PubMed]

110. Ehling-Schulz, M.; Lereclus, D.; Koehler, T.M. The Bacillus cereus group: Bacillus species with pathogenic potential. Microbiol. Spectr. 2019, 7, 3-7. [CrossRef]

111. Tran, S.-L.; Ramarao, N. Bacillus cereus immune escape: A journey within macrophages. FEMS Microbiol. Lett. 2013, $347,1-6$. [CrossRef] 
112. Bravo, A.; Likitvivatanavong, S.; Gill, S.S.; Soberón, M. Bacillus thuringiensis: A story of a successful bioinsecticide. Insect Biochem. Mol. Biol. 2011, 41, 423-431. [CrossRef] [PubMed]

113. Radhakrishnan, R.; Hashem, A.; Abd_Allah, E.F. Bacillus: A biological tool for crop improvement through bio-molecular changes in adverse environments. Front. Physiol. 2017, 8, 667. [CrossRef] [PubMed]

114. Parapouli, M.; Vasileiadis, A.; Afendra, A.-S.; Hatziloukas, E. Saccharomyces cerevisiae and its industrial applications. AIMS Microbiol. 2020, 6, 1. [CrossRef] 